\title{
A Monopolar Symmetrical Hybrid Cascaded DC/DC Converter for HVDC Interconnections
}

\author{
Shuxin Zhang, Binbin Li, Member, IEEE, Da Cheng, Xiaodong Zhao, Gen Li, Member, IEEE, \\ Wei Wang, Member, IEEE, and Dianguo Xu, Fellow, IEEE
}

\begin{abstract}
With the rapid development of voltage source converter (VSC) based high voltage direct current (HVDC) transmission, it is an irresistible trend that HVDC grid will come into being. High-voltage and high-power DC/DC converters will serve as DC transformers in HVDC grid to interconnect DC lines with different voltage ratings. This paper proposes a monopolar symmetrical DC/DC converter which is composed of cascaded half-bridge sub-modules (SMs) and series-connected IGBTs. This hybrid topology features low capital costs, high efficiency, small footprint, and bidirectional power transfer capability. Operation principle, parameter design, and the control strategies of this topology are introduced. $\mathrm{A} 480 \mathrm{MW}, \pm 500 \mathrm{kV} / \pm 160 \mathrm{kV}$ monopolar symmetrical DC/DC converter is simulated to verify its performance and evaluate the efficiency. In addition, a downscaled prototype rated at $2.4 \mathrm{~kW}, \pm 300 \mathrm{~V} / \pm 100 \mathrm{~V}$ has been built and tested. Experimental results further validate the effectiveness of the proposed DC/DC converter.
\end{abstract}

Index Terms-Monopolar symmetrical DC/DC converter, hybrid topology, DC transformer, HVDC grid.

\section{INTRODUCTION}

A $\mathbf{S}$ a milestone achievement in power electronics, modular multilevel converter (MMC) has significantly facilitated voltage source converter (VSC) based high voltage direct current (HVDC) transmission technology [1]-[3]. In the last decade, dozens of MMC-HVDC projects with different voltage ratings have been constructed worldwide. For flexibility and reliability purposes, multi-terminal and meshed HVDC grids have been getting widespread attention of the academia and industry [4]-[9]. In such a trend, DC/DC converter for matching different voltage ratings will be one of the most crucial devices in future HVDC grids.

With regard to HVDC interconnections, DC/DC converters should be scalable up to hundreds of kilovolts and hundreds of megawatts [10]-[12]. Facing the problems of limited semiconductor voltage rating, high $\mathrm{d} v / \mathrm{d} t$, high losses, and large filter size, most of the classic DC/DC converter topologies are not qualified for this application. Enlightened by the MMC concept that using series connection of sub-modules (SMs) to realize efficient high-voltage high-power conversion, modular DC/DC converter topologies have been proposed which can solve the problems. In terms of whether there is galvanic isolation between the DC input and output, these modular DC/DC converters are classified into two categories, namely isolated types [13]-[17] and non-isolated types [18]-[31].

This work was supported in part by the National Natural Science Foundation of China under Grants 51807033 and 51720105008 . (Corresponding author: Binbin $\mathrm{Li}$ )

S. Zhang, B. Li, X. Zhao, W. Wang and D. Xu are with the School of Electrical Engineering and Automation, Harbin Institute of Technology, Harbin

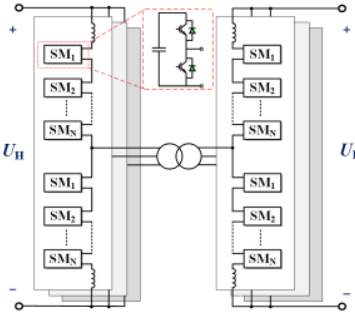

(a) FTF-MMCs

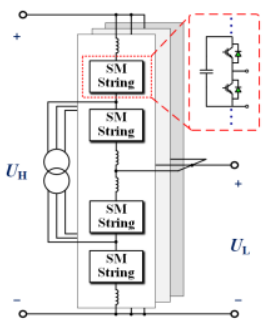

(c) ATDC

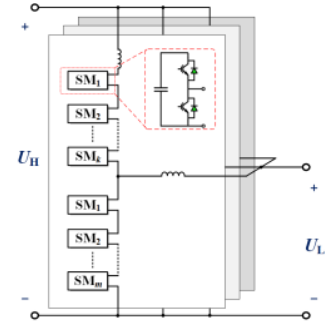

(b) MMDC

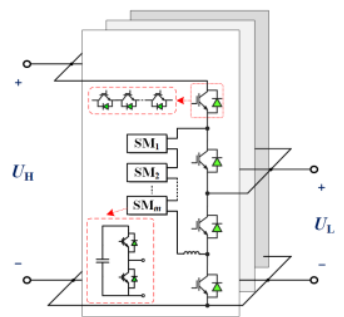

(d) $\mathrm{HCDC}$
Fig. 1. The existing modular DC/DC topologies for HVDC interconnections.

The most common isolated topology is the front-to-front (FTF)-MMCs shown in Fig. 1(a), which consists of two MMCs and an AC link transformer [13]-[17]. It inherits the distinctive features of MMC and presents good scalability of voltage and power rating. However, there are two power conversion stages, thus it exhibits significant large number of semiconductors, which causes high losses, and requires a full power AC transformer. Using medium-frequency (several hundred $\mathrm{Hz}$ ) transformer [13]-[14] or trapezoidal-waveform transformer [15]-[17] can help shrink the size and weight of the AC transformer, but this is at the expense of much more difficult insulation and cooling design on account of the induced eddycurrent losses in magnetic core as well as the windings. In summary, the FTF-MMCs are not suitable for HVDC interconnections with similar voltage rating but more viable for conversion between high-voltage and medium-voltage systems which has a high DC voltage ratio [10].

As for low $(1<$ ratio $\leq 1.5)$ and medium $(1.5<$ ratio $\leq 5)$ voltage ratio connections, non-isolated topologies are more attractive. Compared with the FTF-MMCs, modular multilevel DC/DC converter (MMDC) topologies [18]-[24] have been proposed which have only one conversion stage and do not need the AC link transformer. As shown in Fig. 1(b), part of its SMs can be

150001, China (e-mail: zhang_shu_xin@126.com; libinbin@hit.edu.cn; 2423432170@qq.com; wangwei602@hit.edu.cn; xudiang@hit.edu.cn).

D. Cheng is with the CRRC Qingdao SIFANG Rolling Stock Research Institute CO., LTD, Qingdao 266000, China (e-mail: 374949298@qq.com).

$\mathrm{G}$. Li is with the School of Engineering, Cardiff University, Cardiff CF24 3AA, UK (e-mail: LiG9@ cardiff.ac.uk). 


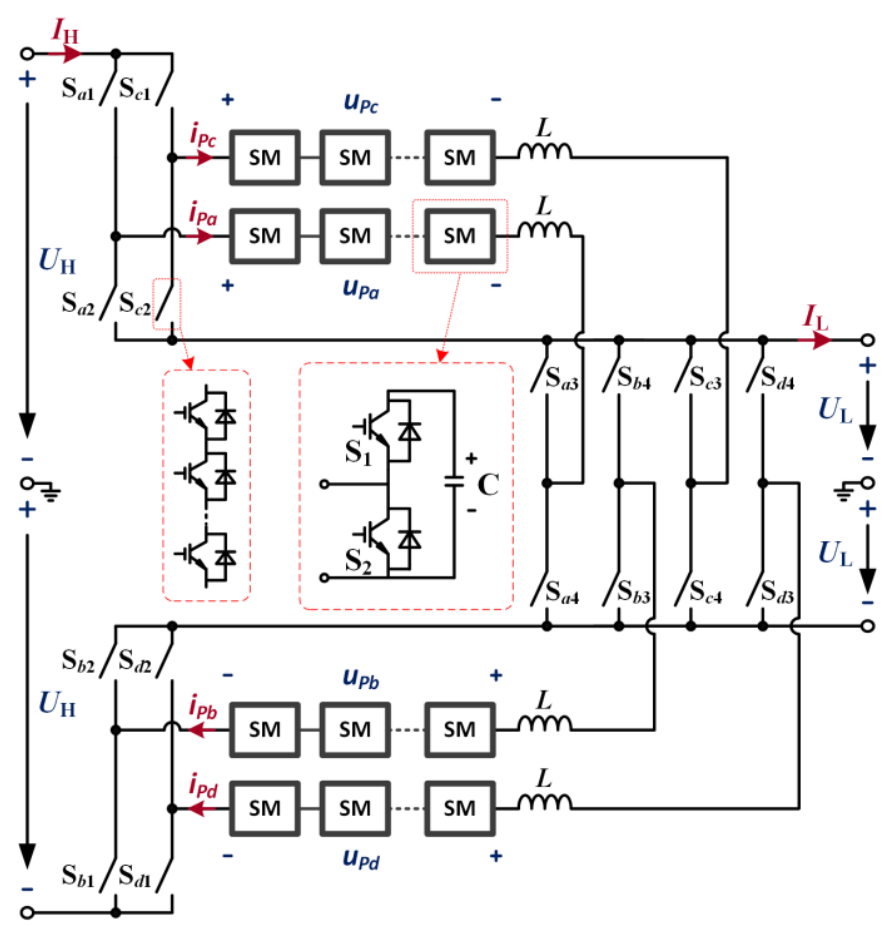

Fig. 2. Configuration of the proposed monopolar symmetrical hybrid cascaded DC/DC converter (MS-HCDC) topology.

utilized by both of the high-voltage (HV) and low-voltage (LV) DC sides, so the number of the semiconductors can be reduced. However, in order to maintain the power balance of the SM capacitors, AC voltages and currents must be injected. As a result, the current stress and power losses are both significant and a large reactor is required at the DC output to filter the injected AC voltages. To avoid using the reactor, additional SM strings have been utilized in [23] and [24] to actively attenuate the injected AC voltages, but this is at the expense of higher semiconductor count and power losses.

Another non-isolated topology is the auto-transformer principle based DC/DC converter (ATDC), as shown in Fig. 1(c), which is composed of two MMCs connected in series on the DC ports, and a partial-power AC transformer is utilized to link the AC ports [25]. Since a portion of power can be transferred directly through the DC path, the power losses and rating of the AC transformer can be reduced. In addition, ATDC can be conveniently extended to a multiport topology [26]. However, the AC transformer in ATDC should be designed to withstand large DC offset voltage stress across the windings, which will significantly increase costs and size compared to a conventional transformer of equivalent power rating [27]. In [28] and [29], the flying capacitors have been utilized to replace the AC transformer in ATDC, but the flying capacitors should accommodate large DC voltage rating and high current stress, which increases weight, volume and manufacture difficulty. In [30], additional SM strings, rather than the flying capacitors, have been used, which will obviously increase the semiconductor count and add to capital costs and power losses of the converter.

In order to avoid using large $\mathrm{AC}$ transformer or filtering reactor, a novel hybrid cascaded DC/DC converter (HCDC) has been proposed in [31]. As shown in Fig. 1(d), the HCDC has three phases, each of which consists of four branches of seriesconnected insulated-gate bipolar transistors (IGBTs), a string of cascaded half-bridge SMs, and one buffering inductor. By controlling the IGBT branches, the SM string can be connected in series between the two DC sides to make the SM capacitors charged/discharged and then switched to the LV DC side to make the SM capacitors discharged/charged. In this way, the DC/DC conversion can be realized through the repeated charging and discharging of the SM capacitors. The three phases operate in an interleaving mode to avoid the currents of the two DC sides being discontinuous. Since all the SMs can be utilized by both of the two DC sides, the HCDC has the highest utilization rate of the SMs compared to the above-mentioned topologies. Hence, it features less semiconductors, higher efficiency, and small footprint.

On the other hand, note that all the aforementioned DC/DC topologies are monopolar asymmetrical structure; however, most of the existing VSC-HVDC projects adopt monopolar symmetrical configuration [32]. Therefore, for practical interconnections between monopolar symmetrical HVDC systems, two HCDC converters in cascade are required [19], [23], [29]. However, in this paper, by further effectively utilizing the SM strings by both of the positive and negative DC poles, the HCDC can be integrated into a novel monopolar symmetrical configuration so that the phase number can be reduced from six to four.

The rest of this paper is organized as follows. In Section II the monopolar symmetrical DC/DC converter and its operating principle are illustrated. This is followed by the circuit analysis and parameter dimensioning in Section III. Further, Section IV discusses the control schemes developed for this monopolar symmetrical DC/DC topology. Simulation results are provided in Section V to demonstrate validity of the topology and control schemes, which is followed by experimental results in Section VI. A further discussion and efficiency evaluation are provided in Section VII, and finally the conclusion is given in Section VIII.

\section{MONOPOlAR SYMMETRICAL HYBRID CASCADED DC/DC CONVERTER}

\section{A. Circuit Configuration}

Circuit configuration of the proposed monopolar symmetrical hybrid cascaded DC/DC converter (MS-HCDC) is shown in Fig. 2. It consists of four phases $(j=a, b, c, d)$; each phase is composed of four branches of IGBTs in series connection $\left(S_{j 1}, S_{j 2}, S_{j 3}, S_{j 4}\right)$ and a string of cascaded half-bridge SMs and one buffering inductor $L . U_{\mathrm{H}}$ is the voltage of the $\mathrm{HV}$ DC side while $U_{\mathrm{L}}$ is the LV DC side voltage. $I_{\mathrm{H}}$ and $I_{\mathrm{L}}$ are the currents of the $\mathrm{HV}$ and LV sides, respectively. $i_{P j}$ is the SM string current, and $u_{P j}$ is the SM string voltage.

\section{B. Operation Principle of One Phase of the MS-HCDC}

Operation principle of one phase of the MS-HCDC is shown in Fig. 3, in which phase $a$ is taken as an example and the power is transferred from the HV side to the LV side. $u_{\mathrm{S} a 1} \sim u_{\mathrm{S} a 4}$ are the voltages of the IGBT branches, $u_{L}$ is the voltage across the buffering inductor, and $T_{\mathrm{h}}$ is the operation cycle. 


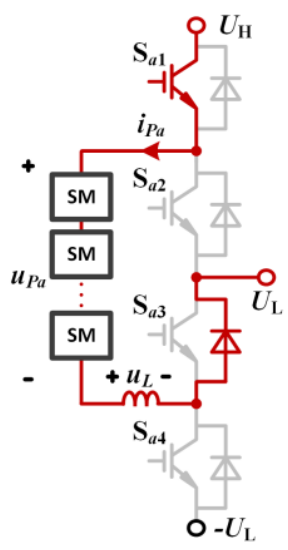

Stage $\left[t_{0}, t_{5}\right]$

(a)

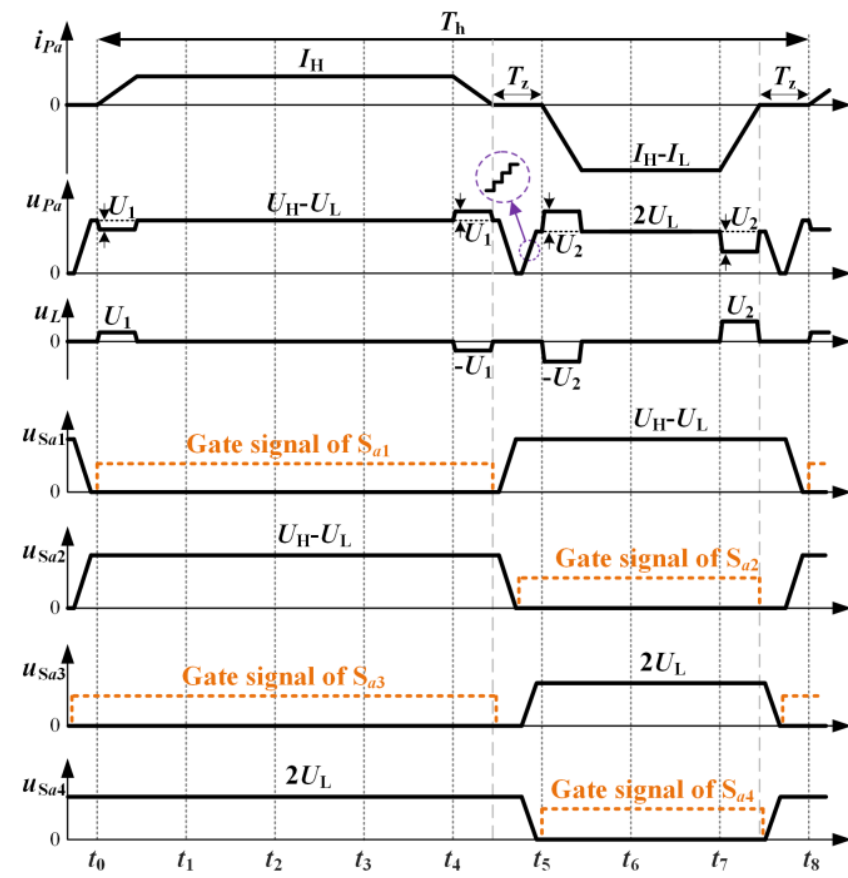

(c)

Fig. 3. Operation principle of phase $a$ of the MS-HCDC. (a) Circuit during $\left[t_{0}\right.$, $t_{5}$ ]. (b) Circuit during $\left[t_{5}, t_{8}\right]$. (c)Waveforms.

During $\left[t_{0}, t_{5}\right], S_{a 1}$ and $S_{a 3}$ are in on state while $S_{a 2}$ and $S_{a 4}$ are in off state, thus the SM string is inserted between the positive poles of the HV and LV DC sides, as shown in Fig. 3(a). The string voltage $u_{P a}$ accommodates $U_{\mathrm{H}}-U_{\mathrm{L}}$ to control the string current to flow through $S_{a 1}$ and $S_{a 3}$, and the SM capacitors are charged. As shown in Fig. 3(c), $i_{P a}$ is regulated as a trapezoid waveform whose amplitude is $I_{\mathrm{H}}$. During $i_{P a}$ rising/falling process, $u_{P a}$ should be adjusted to impose a positive/negative current driving voltage $U_{1}$ across the buffering inductor. Capacitors of the SMs in the string are charged and the total energy absorbed by the SM string during $\left[t_{0}, t_{5}\right]$ can be derived as

$$
\begin{aligned}
\Delta E_{\text {charge }} & =\int_{t_{0}}^{t_{5}} u_{P a} i_{P a} \mathrm{~d} t=\int_{t_{0}}^{t_{4}}\left(U_{\mathrm{H}}-U_{\mathrm{L}}\right) I_{\mathrm{H}} \mathrm{d} t \\
& =\frac{1}{2} T_{\mathrm{h}} I_{\mathrm{H}}\left(U_{\mathrm{H}}-U_{\mathrm{L}}\right)
\end{aligned}
$$

During $\left[t_{5}, t_{8}\right], \mathrm{S}_{a 2}$ and $\mathrm{S}_{a 4}$ are in on state and $\mathrm{S}_{a 1}$ and $\mathrm{S}_{a 3}$ are in off state. The SM string is connected in parallel with the LV DC side, as shown in Fig. 3(b). $u_{P a}$ is controlled to match $2 U_{\mathrm{L}}$ and $i_{P a}$ flows through $\mathrm{S}_{a 2}$ and $\mathrm{S}_{a 4}$ which discharges the SM capacitors. As shown in Fig. 3(c), $i_{P a}$ is controlled as a trapezoid waveform with amplitude of $I_{\mathrm{H}}-I_{\mathrm{L}}$. A negative/positive current driving voltage $U_{2}$ is imposed across the buffering inductor during $i_{P a}$ falling/rising process. In $\left[t_{5}, t_{8}\right]$, the $S M$ capacitors get discharged and the total energy released by the SM string is

$$
\begin{aligned}
\Delta E_{\text {discharge }} & =\int_{t_{5}}^{t_{8}} u_{P a} i_{P a} \mathrm{~d} t=\int_{t_{5}}^{t_{7}} 2 U_{\mathrm{L}}\left(I_{\mathrm{H}}-I_{\mathrm{L}}\right) \mathrm{d} t \\
& =\frac{1}{2} T_{\mathrm{h}} U_{\mathrm{L}}\left(I_{\mathrm{H}}-I_{\mathrm{L}}\right)
\end{aligned}
$$

Summation of (1) and (2) yields the energy variation of the SM string in a cycle, that is

$$
\Delta E=\Delta E_{\text {charge }}+\Delta E_{\text {discharge }}=\frac{1}{2} T_{\mathrm{h}}\left(U_{\mathrm{H}} I_{\mathrm{H}}-U_{\mathrm{L}} I_{\mathrm{L}}\right)
$$

where $2 U_{\mathrm{H}} I_{\mathrm{H}}$ and $2 U_{\mathrm{L}} I_{\mathrm{L}}$ represent the HV side and LV side DC power of the MS-HCDC, respectively, and when neglecting the converter losses, they are equal. Hence $\Delta E$ is zero, which means the absorbed and released energy over one cycle are balanced. In practice, the amplitudes of the string current during charging and discharging stages are controlled independently. One amplitude is used to regulate the power of the converter, and the other amplitude is adjusted to ensure the absorbed energy somewhat higher than the released energy so as to compensate power losses of the converter.

In addition, during the transition between the stages $\left[t_{0}, t_{5}\right]$ and $\left[t_{5}, t_{8}\right]$, an interval $T_{\mathrm{Z}}$ is designed where the $i_{P a}$ is kept zero. It can be observed in Fig. 3(c) that $S_{a 1} \sim S_{a 4}$ are all switched within $T_{\mathrm{z}}$, so that the zero-current switching (ZCS) for the IGBT branches is guaranteed. Moreover, by appropriately adjusting the string voltage $u_{P a}$, the voltages across $\mathrm{S}_{a 1} \sim \mathrm{S}_{a 4}\left(u_{\mathrm{S} a 1} \sim u_{\mathrm{S} a 4}\right)$ can be controlled to be zero as well for achieving zero-voltage switching (ZVS). For instance, when switching off $S_{a 1}$ and $S_{a 3}$, the $u_{P a}$ voltage can be kept at $U_{\mathrm{H}^{-}} U_{\mathrm{L}}$, thus $u_{\mathrm{S} a 1}$ and $u_{\mathrm{S} a 3}$ are maintained zero. On the other hand, before switching on $S_{a 2}$, $u_{\mathrm{Pa}}$ is decreased to zero, as a result $u_{\mathrm{S} a 2}$ becomes zero and ZVS turn-on of $\mathrm{S}_{a 2}$ is realized. Afterwards, $u_{P a}$ is increased to match $2 U_{\mathrm{L}}, u_{\mathrm{S} a 4}$ drops to zero accordingly and $\mathrm{S}_{a 4}$ also turns on at ZVS condition. Likewise, when switching on $S_{a 1}$ and $S_{a 3}$ while switching off $S_{a 2}$ and $S_{a 4}$, the ZVS condition can also be created. Therefore, the variation of string voltage $u_{P a}$ is $U_{\mathrm{H}^{-}}$ $U_{\mathrm{L}}+2 U_{\mathrm{L}}=U_{\mathrm{H}}+U_{\mathrm{L}}$ during $T_{\mathrm{z}}$, whose length should be designed to limit $\mathrm{d} v / \mathrm{d} t$, i.e., $\left(U_{\mathrm{H}}+U_{\mathrm{L}}\right) / T_{\mathrm{z}}$.

In summary, all the IGBT branches can be switched on and off under the zero voltage zero current switching (ZVZCS) condition. Besides, to avoid causing excessive $\mathrm{d} v / \mathrm{d} t$ in the waveform of $u_{P a}$, the SMs in the string are switched sequentially, which results in a staircase-shaped transition waveform [17], as shown in Fig. 3(c). 


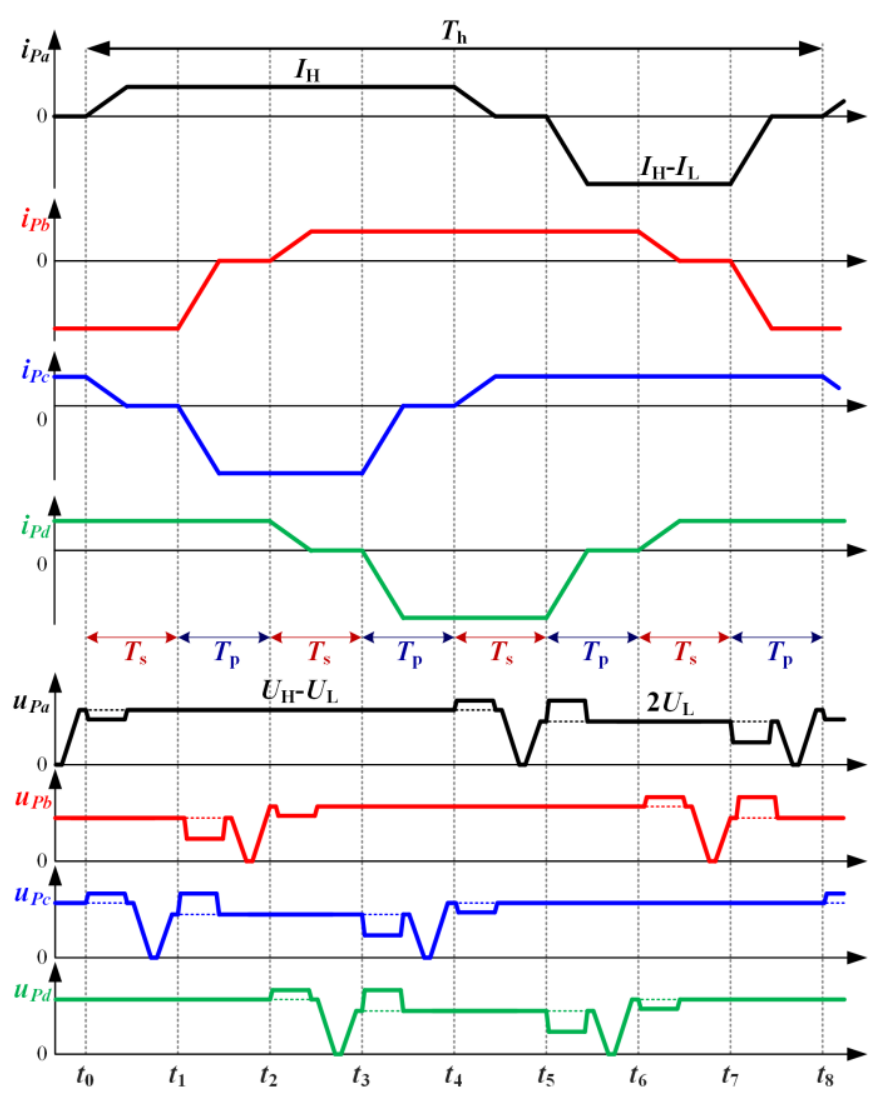

Fig. 4. Operation waveforms of the MS-HCDC.

\section{Operation Principle of the MS-HCDC}

Based on the above discussion of each phase, operation waveforms of the complete MS-HCDC with four phases are further shown in Fig. 4. Actually, the current and voltage waveforms of the four phases are identical but interleaved with $90^{\circ}$ electrical angle. In each cycle $T_{\mathrm{h}}$, it can be divided into eight intervals. During interval $\left[t_{0}, t_{1}\right]$, the circuit configuration is shown in Fig. 5(a), where string $b$ (coloured red) is in parallel with the LV side, string $d$ (coloured green) is inserted between the negative poles of $\mathrm{HV}$ and LV sides, and strings $a$ and $c$ (coloured black and blue, respectively) are both inserted between the positive poles of HV and LV sides. During this interval, $i_{P b}$ remains invariant at $I_{\mathrm{H}}-I_{\mathrm{L}}$ and $i_{P d}$ remains $I_{\mathrm{H}}$, respectively. However, current commutation happens between $i_{P a}$ and $i_{P c} . i_{P a}$ increases from 0 to $I_{\mathrm{H}}$ whereas $i_{P c}$ decreases from $I_{\mathrm{H}}$ to 0 , and they have the same changing rate. As a result, for the HV side, current of the positive pole, which is $i_{P a}+i_{P c}$, and current of the negative pole, which is $i_{P d}$, are both maintained to be a constant DC value, i.e., $I_{\mathrm{H}}$. With regard to the $\mathrm{LV}$ currents, which is $i_{P a}+i_{P C}-i_{P b}$ for the positive pole and $i_{P d}-i_{P b}$ for the negative pole, ensure to be constant $I_{\mathrm{L}}$.

On the other hand, during the next interval $\left[t_{1}, t_{2}\right]$ as shown in Fig. 5(b), stings $b$ and $c$ are connected in parallel with the LV DC side, and strings $a$ and $d$ are inserted between the positive poles and negative poles of HV and LV sides, respectively. In this case, $i_{P a}$ and $i_{P d}$ remain $I_{\mathrm{H}}$ thus the current of $\mathrm{HV}$ side is constant $I_{\mathrm{H}}$. Meanwhile, the current commutation happens between string $b$ and $c$, that $i_{P b}$ changes from $I_{\mathrm{H}}-I_{\mathrm{L}}$ to 0 whereas $i_{P c}$ changes from 0 to $I_{\mathrm{H}}-I_{\mathrm{L}}$ at the same rate, thus summation of

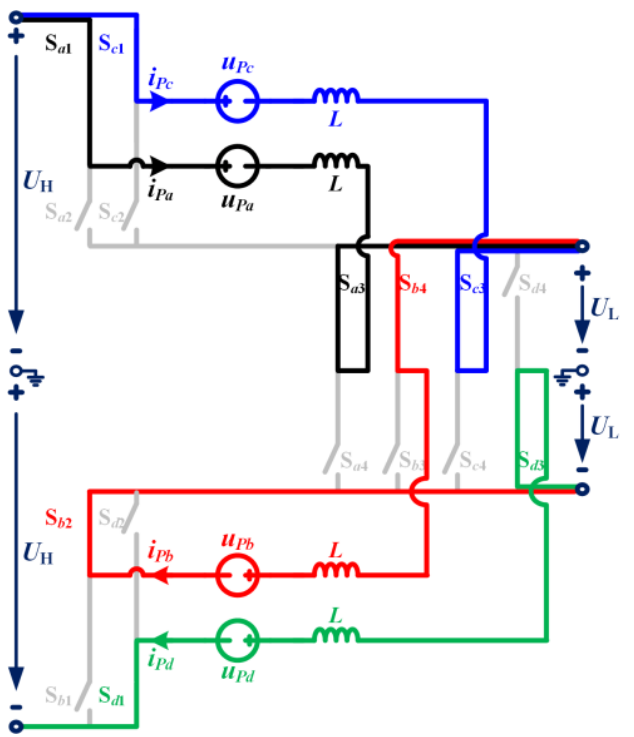

(a) $\left[t_{0}, t_{1}\right]$

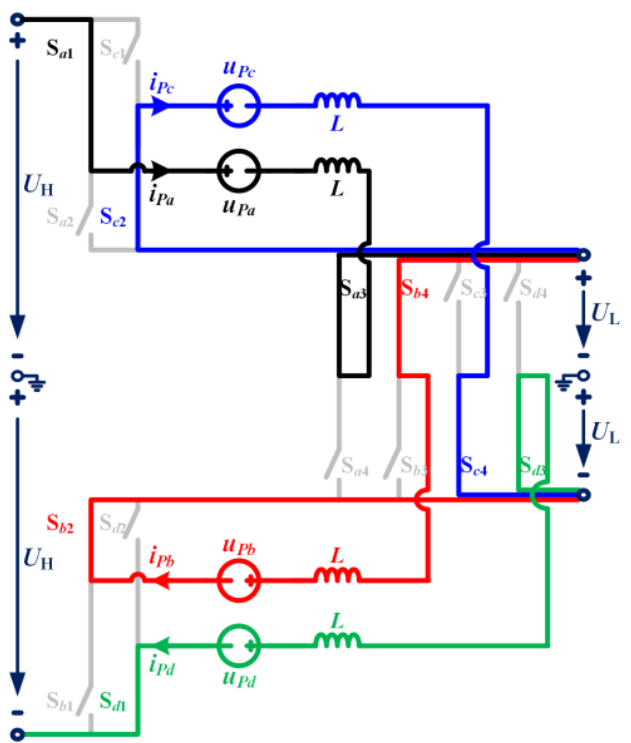

(b) $\left[t_{1}, t_{2}\right]$

Fig. 5. Circuits of the MS-HCDC during $\left[t_{0}, t_{1}\right]$ and $\left[t_{1}, t_{2}\right]$.

$i_{P b}$ and $i_{P C}$ is kept as $I_{\mathrm{H}}-I_{\mathrm{L}}$. Consequently, for the LV side, current of the positive pole, which is $i_{P a}-i_{P b}-i_{P C}$, and current of the negative pole, which is $i_{P d}-i_{P b}-i_{P C}$, are both maintained to be a constant $\mathrm{DC}$ value, i.e., $I_{\mathrm{L}}$.

As shown in Fig. 4, the time length of $\left[t_{0}, t_{1}\right]$ is denoted as $T_{\mathrm{s}}$ and that of $\left[t_{1}, t_{2}\right]$ is denoted as $T_{\mathrm{p}}$. The following six intervals are very similar, with $T_{\mathrm{s}}$ and $T_{\mathrm{p}}$ arranged alternately. In $T_{\mathrm{s}}$, the commutation happens between the two strings which are simultaneously inserted between the positive/negative poles of the two DC sides. In $T_{\mathrm{p}}$, the current commutates between the two strings that are paralleled with the LV side. By this means, the currents of the two DC sides can always keep continuous and the power balance of the SM capacitors in each string is also guaranteed. In addition, no matter during $T_{\mathrm{s}}$ or $T_{\mathrm{p}}$, the output voltage of the proposed MS-HCDC is always supported by one or two strings. Consequently, the output voltage quality would not be affected although the proposed MS-HCDC has fewer phases than the traditional HCDC. 


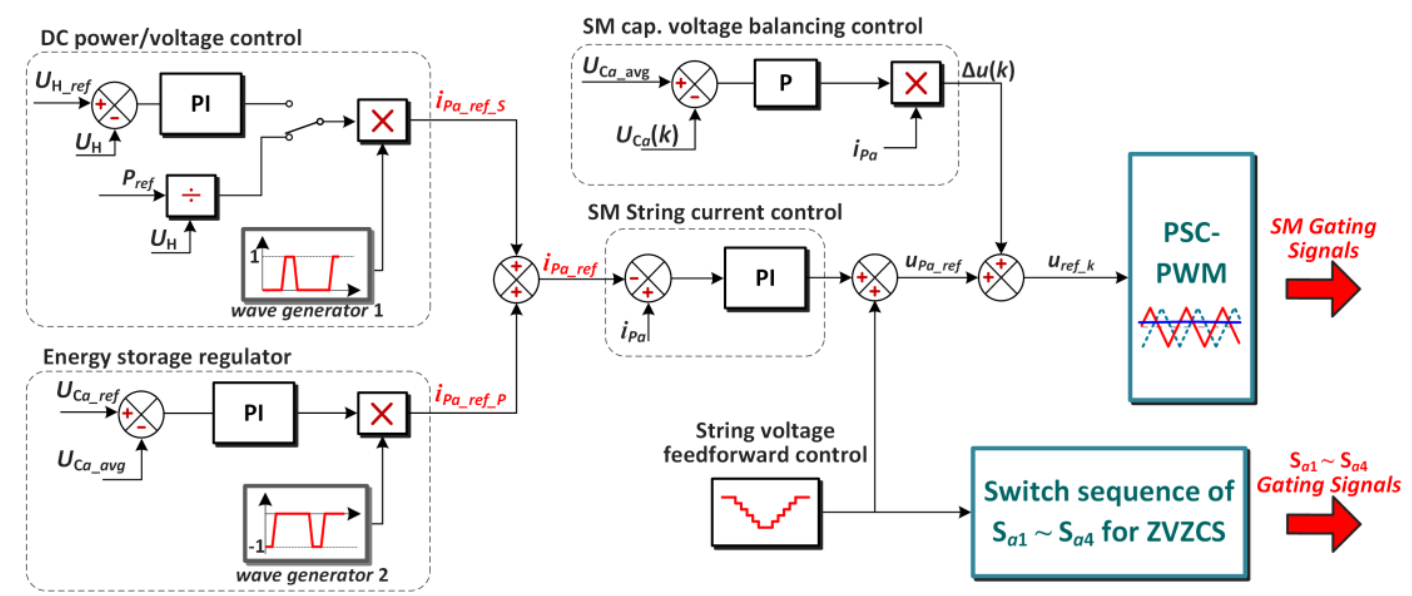

Fig. 6. Control block diagrams for the MS-HCDC.

It is worth noting that, the basic idea of this topology actually lies in the fully utilization of the connectivity of each string, making it able to be parallel with the LV side, inserted between the positive poles, and inserted between the negative poles of two DC sides. On this basis, two traditional HCDCs are integrated into the proposed MS-HCDC. As consequence, four phases of circuit are sufficient to maintain continuous DC currents and it is not necessary to have a total of six phases of circuit as in the conventional HCDC to realize the monopolar symmetrical DC/DC conversion. A large amount of SMs and IGBTs can therefore be saved and the conversion efficiency is improved.

\section{Circuit Analysis AND Design}

\section{A. Sub-Modules}

For each SM string, summation of the SM output voltages should be able to provide the required maximum value for matching $U_{\mathrm{H}}-U_{\mathrm{L}}$ or $2 U_{\mathrm{L}}$ plus an extra current driving voltage $U_{1}$ or $U_{2}$. Note that $U_{1}$ and $U_{2}$ can be determined based on the voltage-second relation of the buffering inductor, that is

$$
\left\{\begin{array}{l}
U_{1}=L \frac{I_{\mathrm{H}}}{T_{\mathrm{s}}-T_{\mathrm{z}}} \\
U_{2}=L \frac{I_{\mathrm{L}}-I_{\mathrm{H}}}{T_{\mathrm{p}}-T_{\mathrm{z}}}
\end{array}\right.
$$

where $T_{\mathrm{s}}-T_{\mathrm{z}}$ and $T_{\mathrm{p}}-T_{\mathrm{z}}$ are the corresponding time durations for current rising/falling. As shown in Fig. $4, T_{\mathrm{h}}$ is equal to $4\left(T_{\mathrm{s}}+T_{\mathrm{p}}\right)$, so larger $U_{1}$ and $U_{2}$ are required if $T_{\mathrm{h}}$ is reduced.

Therefore, taking no account of redundancy, the required number of SMs in each SM string can be then calculated as

$$
N=\frac{\max \left[U_{\mathrm{H}}-U_{\mathrm{L}}+U_{1}, 2 U_{\mathrm{L}}+U_{2}\right]}{U_{\mathrm{C}}}
$$

where $U_{\mathrm{C}}$ is the nominal capacitor voltage of SMs.

Thus, the total number of IGBTs in each SM string of the MS-HCDC is $2 N$. The current stress of the IGBTs in SMs depends on the maximum value of the string current, which is

$$
I_{\text {stress }}=\max \left[I_{\mathrm{H}}, I_{\mathrm{L}}-I_{\mathrm{H}}\right] \text {. }
$$

\section{B. SM Capacitance}

The SM capacitors should be designed to withstand the energy fluctuations of each SM string. The maximum energy variation of one SM string can be evaluated by the energy absorbed by the SM string in a cycle, as presented in (1). This energy variation will be buffered by the $N$ SM capacitors in the string, hence the following equation can be obtained:

$$
\Delta E_{\text {charge }}=\frac{1}{2} N C\left(U_{\mathrm{C}, \text { max }}^{2}-U_{\mathrm{C}, \text { min }}^{2}\right)=N C \varepsilon U_{\mathrm{C}}^{2}
$$

where $\varepsilon$ is the specified relative voltage ripple of the SM capacitor. By substituting (1) into (7), the required SM capacitance can be derived as

$$
C=\frac{T_{\mathrm{h}} I_{\mathrm{H}}\left(U_{\mathrm{H}}-U_{\mathrm{L}}\right)}{2 N \varepsilon U_{\mathrm{C}}^{2}} .
$$

\section{Series-Connected IGBTS}

For realizing high-voltage switch (several hundred $\mathrm{kV}$ ), the IGBT branches must be composed of series-connected IGBTs. According to Fig. 3, the IGBT branches $S_{j 1}$ and $S_{j 2}$ should withstand the voltage of $U_{\mathrm{H}}-U_{\mathrm{L}}$, while $\mathrm{S}_{j 3}$ and $\mathrm{S}_{j 4}$ should withstand the voltage of $2 U_{\mathrm{L}}$. Therefore, the number of seriesconnected IGBTs can be expressed as

$$
\left\{\begin{array}{l}
N_{1,2}=\frac{U_{\mathrm{H}}-U_{\mathrm{L}}}{\lambda_{\mathrm{d}} U_{\mathrm{B}}} \\
N_{3,4}=\frac{2 U_{\mathrm{L}}}{\lambda_{\mathrm{d}} U_{\mathrm{B}}}
\end{array}\right.
$$

where $N_{1,2}$ and $N_{3,4}$ represent the required number of seriesconnected IGBTs in $S_{j 1}$ and $S_{j 2}$, and $S_{j 3}$ and $S_{j 4}$, respectively, $U_{B}$ is the rated blocking voltage of each single IGBT, and $\lambda_{\mathrm{d}}$ is the voltage derating factor in terms of series connection, which ensures voltage margin for a single IGBT [33]. In practice, $\lambda_{\mathrm{d}}$ is selected for example 56\% in the ABB design [34] and 57\% in the GE design [35]. It is noteworthy that the ZVZCS of the IGBT branches can significantly ease the technical difficulty of series connection of IGBTs.

As for the current stress of the series-connected IGBTs, according to Fig. 3, the current stress of $S_{j 1}$ and $S_{j 3}$ is $I_{\mathrm{H}}$, and the current stress of $\mathrm{S}_{j 2}$ and $\mathrm{S}_{j 4}$ is $I_{\mathrm{L}}-I_{\mathrm{H}}$, respectively. 

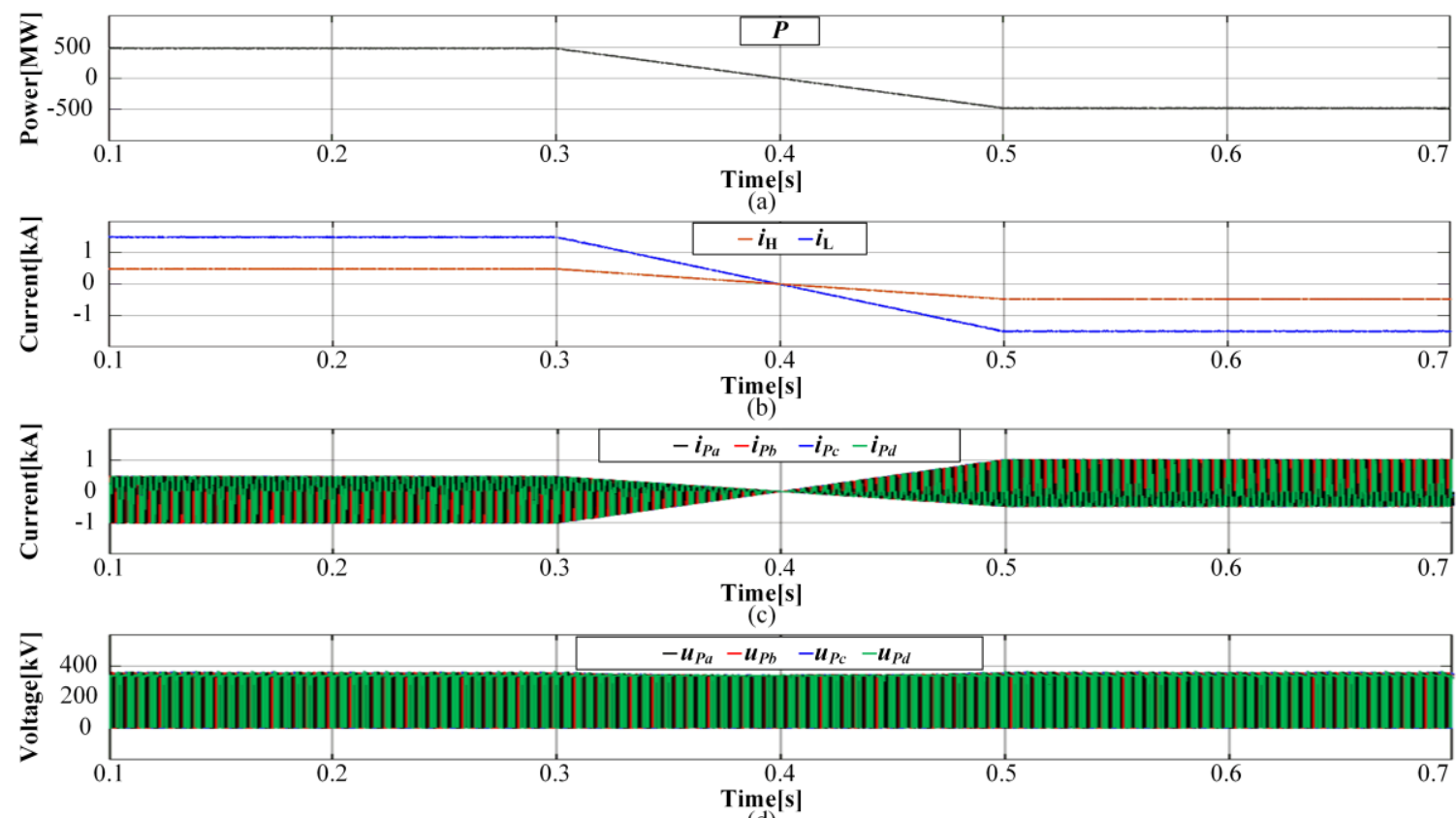

(d)
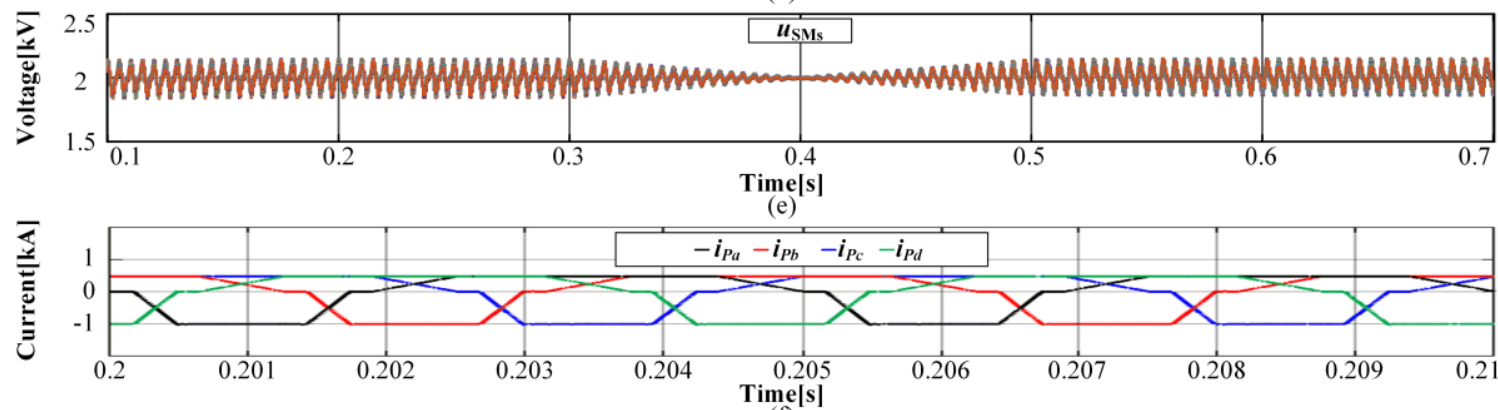

$\underset{(f)}{\operatorname{Time}}[\mathbf{s}]$



(g)

Fig. 7. Simulation results of the MS-HCDC.

\section{String Inductance}

The string inductors should be designed according to the requirement of switching ripple of the string currents, which satisfy

$$
\Delta i=\frac{U_{\mathrm{C}}}{2 L N f_{\mathrm{c}}}
$$

where $\Delta i$ is the switching ripple of string current, $f_{\mathrm{c}}$ is the carrier frequency of the phase shifted carrier pulse-width modulation (PSC-PWM) and $N f_{\mathrm{c}}$ is the equivalent switching frequency of string voltage $u_{P j}$.

\section{CONTROL SCHEMES}

Appropriate control schemes for the MS-HCDC topology are developed in Fig. 6, in which phase $a$ is taken as an example. The control system is mainly composed of DC power/voltage control, energy storage regulator, SM string current control, string voltage feedforward control, SM capacitor voltage balancing control and PSC-PWM.
There are two control modes in the proposed control schemes, namely DC power control mode and DC voltage control mode. Whether to control DC power or DC voltage depends on the requirement of the HVDC system [36]. When the DC power control mode is desired, the amplitude of the SM string referenced current $i_{\text {Pa_ ref_S }_{S}}$ when inserted between the HV and LV sides is given as $P_{\text {ref }} / U_{\mathrm{H}}$, where the $P_{\text {ref }}$ is the transmission DC power command. On the other hand, when the DC voltage control mode is required, the amplitude of $i_{\text {Pa }_{-} \text {ref }} S$ is generated by proportional-integral (PI) controller acting on the error between the reference $\mathrm{HV}$ side DC voltage $U_{\mathrm{H}_{\text {ref }}}$ minus the measured $\mathrm{HV}$ side voltage $U_{\mathrm{H}}$. Note that the DC power or DC voltage control should coordinate with the HVDC system. To be specific, if the HV and LV side are both connected with DC grids whose voltages are controlled by $\mathrm{AC} / \mathrm{DC}$ converters, the DC/DC converter should operate in DC power control mode. Otherwise, the DC/DC converter should operate in DC voltage 


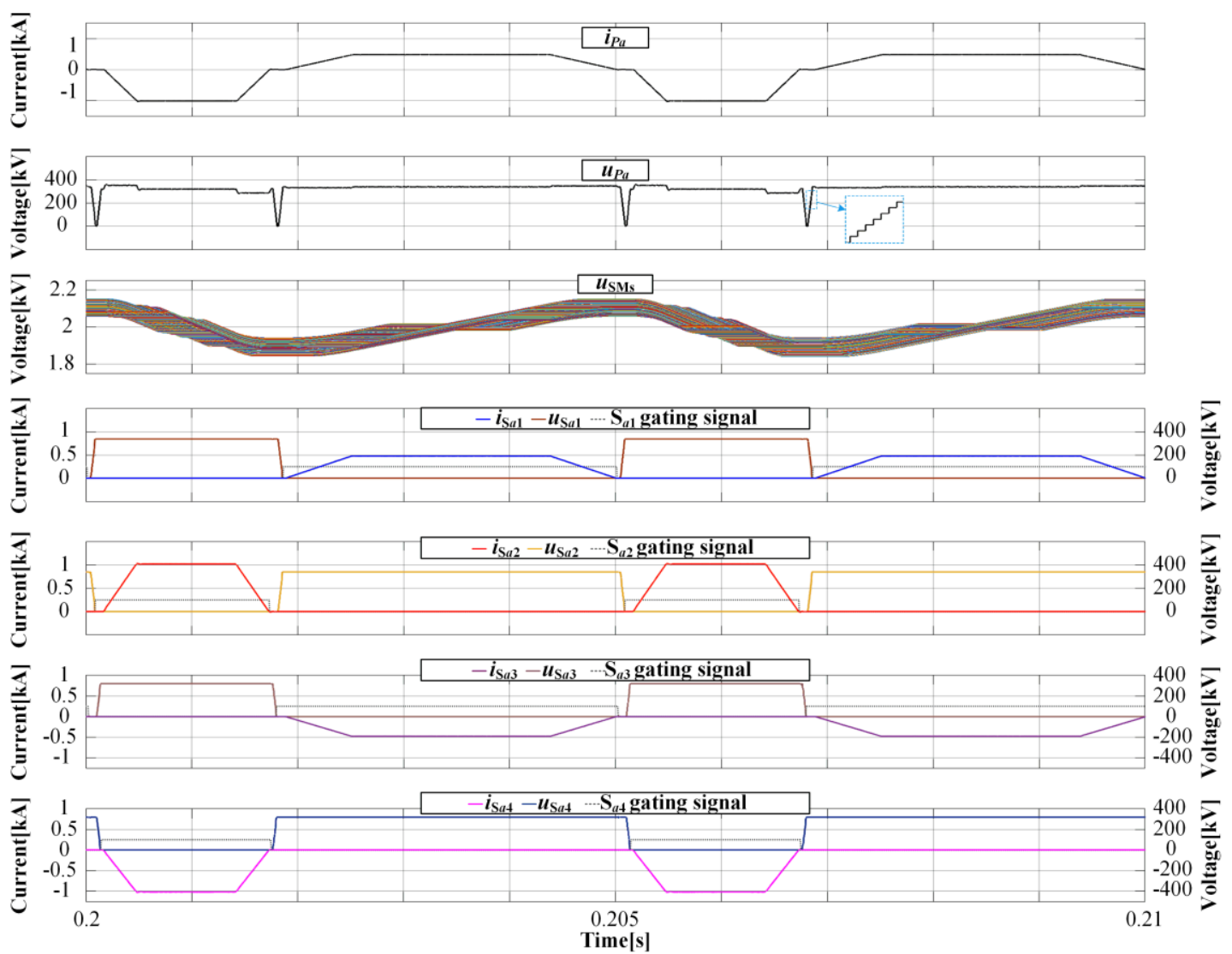

Fig. 8. Detailed simulation results of phase $a$ of the MS-HCDC when rated DC power is transmitted from the HV side to the LV side.

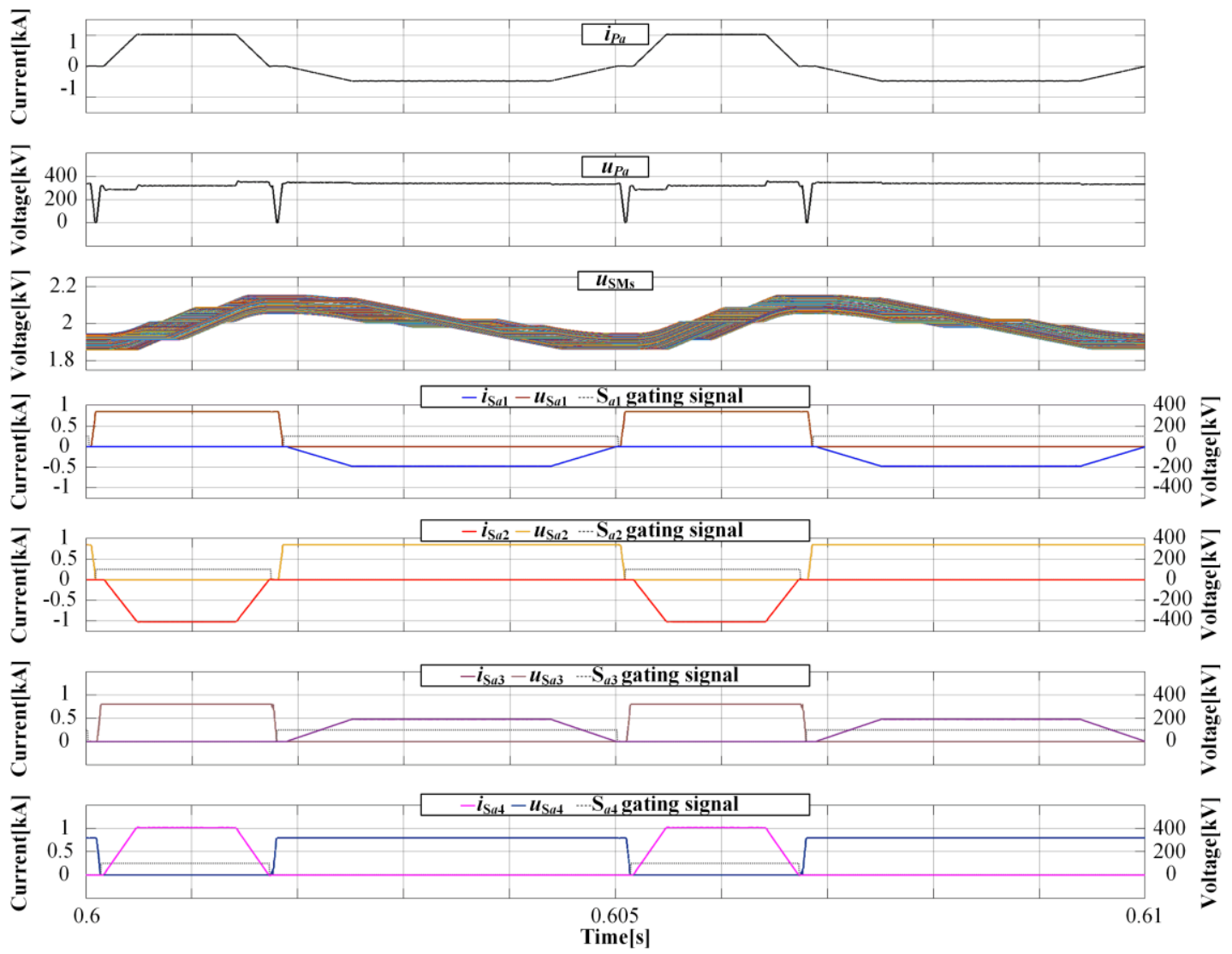

Fig. 9. Detailed simulation results of phase $a$ of the MS-HCDC when rated DC power is transmitted from the LV side to the HV side. 


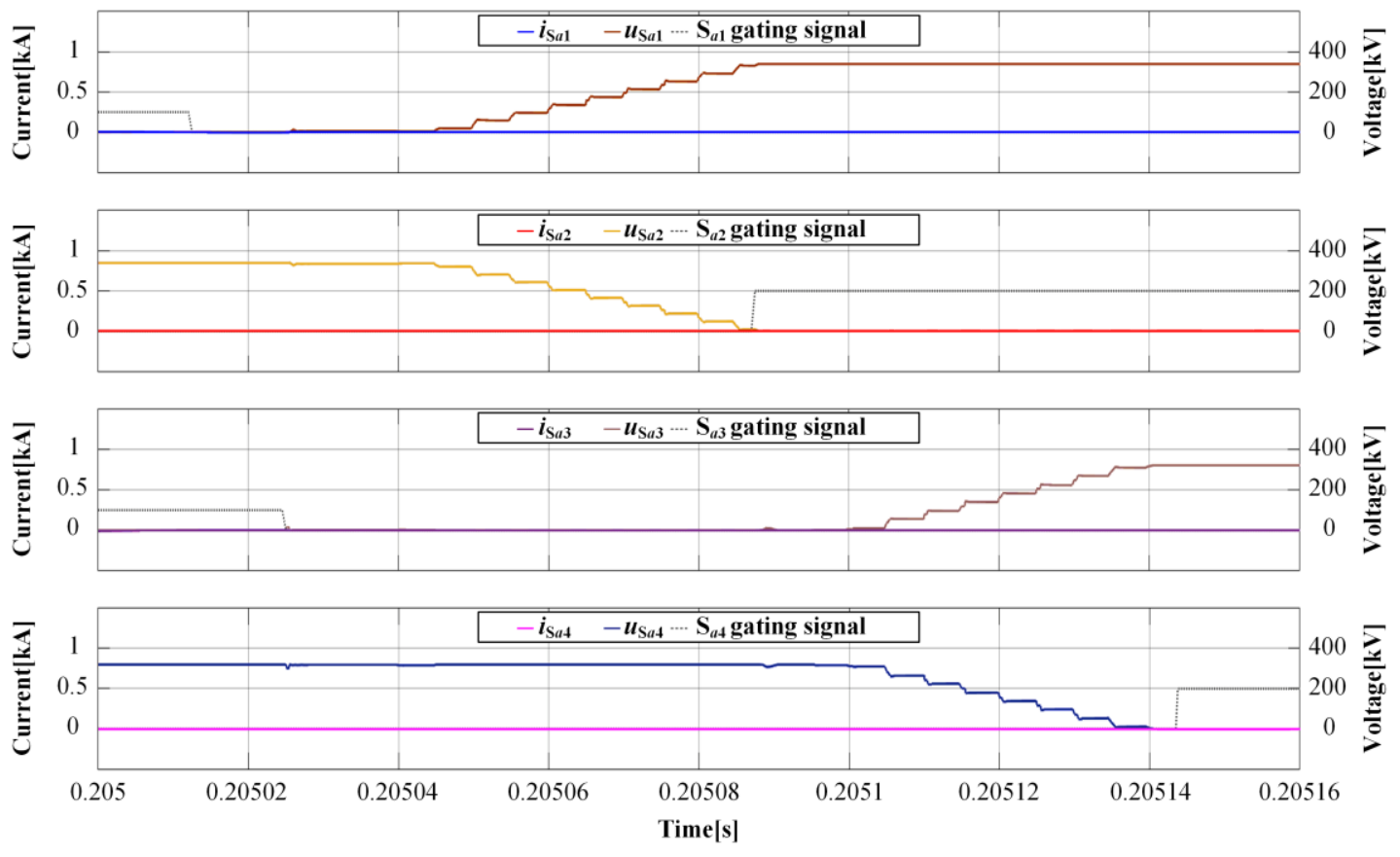

Fig. 10. Simulation results of soft switching process of the IGBT branches.

control mode. For controlling $U_{\mathrm{H}}$, it is effective in the HVDC system where the $\mathrm{AC} / \mathrm{DC}$ converter at the $\mathrm{HV}$ side controls the power and the AC/DC converter at the $\mathrm{LV}$ side stabilizes $U_{\mathrm{L}}$. The trapezoidal shape of $i_{\text {Pa_ref_S }_{-}}$is decided by the wave generator 1 , which will generate a trapezoidal waveform with amplitude of 1 during $\left[t_{0}, t_{5}\right]$ in Fig.3.

The energy storage regulator is used to achieve balance of the stored energy in the string through adjusting the string current when it is connected in parallel with the LV side


PI controller acting on the error between the reference capacitor voltage $U_{\text {Ca_ref }}$ minus the measured average voltage of the SM capacitors $U_{\text {Ca_avg. }}$. When this error deviates from zero, it signifies an imbalance in the energy of the string, thus the PI controller regulates the amplitude of $i_{P a_{-} \text {ref } P}$ to reestablish the balance. The trapezoidal shape of $i_{\text {Pa_ref_P }}$ is decided by the wave generator 2 , which will generate a trapezoidal waveform with amplitude minus 1 during $\left[t_{5}, t_{8}\right]$ in Fig. 3 .

Afterwards, the string current reference $i_{P a_{-} \text {ref }}$ can be obtained by adding $i_{\text {Pa_ref_S }} S$ and $i_{\text {Pa_ref_P }}$. An inner-loop string current control is then used to adjust the string voltage $u_{P a_{-} r e f}$ in order to make $i_{P a}$ follow its reference.

The string voltage feedforward control is applied during $T_{\mathrm{z}}$ in Fig. 3. $u_{P a}$ is gradually decreased from $U_{\mathrm{H}^{-}} U_{\mathrm{L}}$ or $2 U_{\mathrm{L}}$ to zero, and then recovers to $2 U_{\mathrm{L}}$ or $U_{\mathrm{H}}-U_{\mathrm{L}}$, to create the ZVZCS condition for the IGBT branches. And a staircase-shaped waveform of string voltage is utilized to avoid excessive $\mathrm{d} v / \mathrm{d} t$ in the way of inserting (or bypassing) the SMs one by one.

Finally, the string voltage reference $u_{P_{a} \text { ref }}$ is sent to the PSCPWM which synthesizes the SM gating signals. In order to balance the SM capacitor voltage, a controller is utilized for each SM. The error between the capacitor voltage of the $k$ th $(k=1,2, \ldots, N)$ SM $U_{\mathrm{C} a(k)}$ and the average voltage of all the SM capacitors in this string $U_{\mathrm{Ca}_{-} \text {avg }}$ is inputted into a proportional controller. Moreover, in consideration of the direction of the
TABLE I

SiMULATION PARAMETERS

\begin{tabular}{lc}
\hline \hline Converter Parameters & Values \\
\hline Rated DC power & $P=480 \mathrm{MW}$ \\
HV DC voltage & $\pm U_{\mathrm{H}}= \pm 500 \mathrm{kV}$ \\
LV DC voltage & $\pm U_{\mathrm{L}}= \pm 160 \mathrm{kV}$ \\
No. of SMs in each string & $N=200$ \\
Nominal SM capacitor voltage & $U_{\mathrm{C}}=2 \mathrm{kV}$ \\
SM capacitance & $C=5.1 \mathrm{mF}$ \\
SM capacitor voltage ripple & $\varepsilon=10 \%$ \\
PSC carrier frequency & $f_{\mathrm{c}}=550 \mathrm{~Hz}$ \\
Operation cycle & $T_{\mathrm{h}}=5 \mathrm{~ms}$ \\
Buffering inductor & $L=10 \mathrm{mH}$ \\
\hline \hline
\end{tabular}

string current, the output of the proportional controller is further multiplied by $i_{P a}$ to generate the $\Delta u(k)$. Therefore, if the string current charges the SMs (namely, $i_{P a}>0$ ), a positive $\Delta u(k)$ will be generated for the $k$ th SM once its capacitor voltage $U_{\mathrm{C} a(k)}$ is below the average value $U_{\text {Ca_avg. }}$ Afterwards, the voltage reference correction $\Delta u(k)$ is added to the string voltage reference $u_{\text {Pa_ref }}$, which gives the reference voltage of the $k$ th SM $u_{\text {ref } \_} k$, and this can be expressed as

$u_{r e f \_k}=u_{P a_{-} r e f}+\Delta u(k)=u_{P a_{-} r e f}+K_{\mathrm{p}}\left(U_{\mathrm{C} a_{-} \text {avg }}-U_{\mathrm{C} a(k)}\right) \times i_{P a}(11)$ where $K_{\mathrm{p}}$ represents the proportional balancing gain. $u_{r e f-k}$ is compared with the triangular carrier of PSC-PWM and finally generates the gating signal of the SM IGBTs. Under this balancing mechanism, the SMs with higher voltage will absorb less energy (or release more energy), and vice versa [37].

As for the other three phases, the only difference is that each of the wave generators is lagged $90^{\circ}$ electrical angle compared with its previous phase. As a result, continuous HV and LV DC currents can be obtained. 


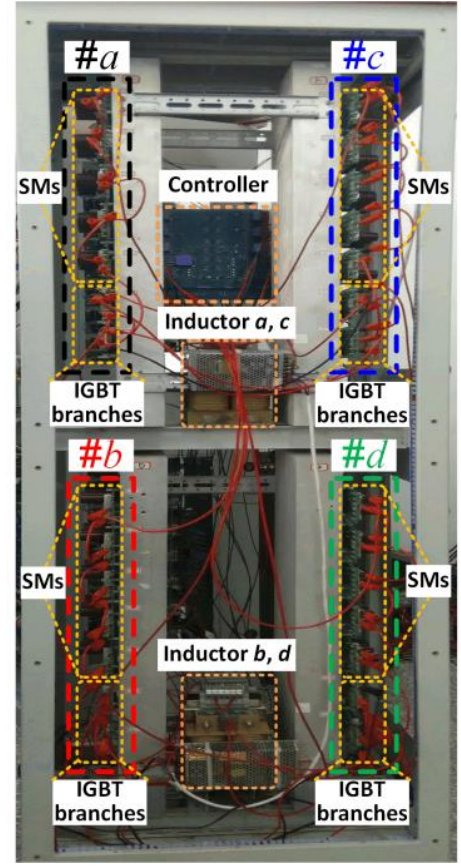

Fig. 11. Photograph of the laboratory MS-HCDC prototype.

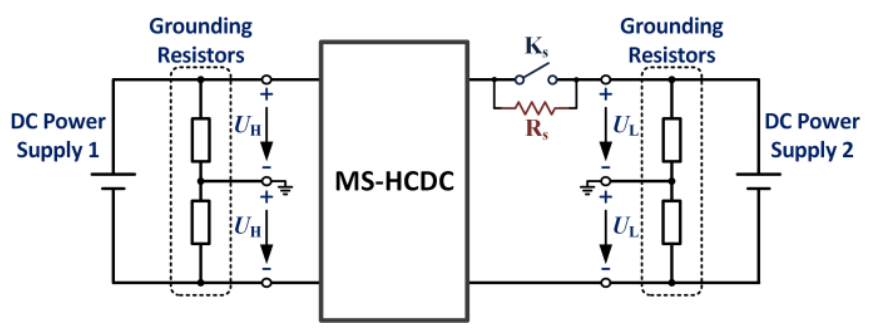

Fig. 12. Configuration of the experimental circuit.

\section{SimUlation STUDY}

In order to verify feasibility of the proposed topology, a $480 \mathrm{MW}, \pm 500 \mathrm{kV} / \pm 160 \mathrm{kV}$ simulation model of the MS-HCDC is performed in MATLAB/SIMULINK. Detailed parameters are listed in Table I. In each SM string, there are 200 SMs and each of them is rated at $2 \mathrm{kV}$.

Fig. 7 presents the bidirectional power flow response of the MS-HCDC. As shown in Fig. 7(a), in the beginning, the converter transmitted rated DC power from the HV side to the LV side; then between $0.3 \mathrm{~s}$ and $0.5 \mathrm{~s}$, the DC power was ramped from $+480 \mathrm{MW}$ down to $-480 \mathrm{MW}$; afterwards, the power was maintained $-480 \mathrm{MW}$, meaning the power flow was reversed completely. Fig. 7(b) shows the currents $\left(i_{\mathrm{H}}\right.$ and $\left.i_{\mathrm{L}}\right)$ of the two DC sides. The currents $\left(i_{P a}, i_{P b}, i_{P c}, i_{P d}\right)$ and voltages $\left(u_{P a}, u_{P b}\right.$, $\left.u_{P c}, u_{P d}\right)$ of the four SM strings are displayed in Figs. 7(c) and (d), respectively. In addition, the capacitor voltages of the 200 SMs in phase $a$ are shown in Fig. 7(e), which were kept well balanced during the whole simulation process. Zoomed currents and voltages of the four SM strings are displayed in Fig. 7(f) and $(\mathrm{g})$. As can be observed, although the shapes and amplitudes of the four SM string currents and voltages are identical, they are interleaved with $90^{\circ}$ electrical angle. Therefore, the currents of the two DC sides maintain continuous
TABLE II

EXPERIMENTAL PARAMETERS

\begin{tabular}{lc}
\hline \hline Converter Parameters & Values \\
\hline Rated DC power & $P=2.4 \mathrm{~kW}$ \\
HV DC voltage & $\pm U_{\mathrm{H}}= \pm 300 \mathrm{~V}$ \\
LV DC voltage & $\pm U_{\mathrm{L}}= \pm 100 \mathrm{~V}$ \\
No. of SMs in each string & $N=5$ \\
Nominal SM capacitor voltage & $U_{\mathrm{C}}=50 \mathrm{~V}$ \\
SM capacitance & $C=3 \mathrm{mF}$ \\
PSC carrier frequency & $f_{\mathrm{c}}=3 \mathrm{kHz}$ \\
Operation cycle & $T_{\mathrm{h}}=10 \mathrm{~ms}$ \\
Buffering inductor & $L=2 \mathrm{mH}$ \\
\hline \hline
\end{tabular}

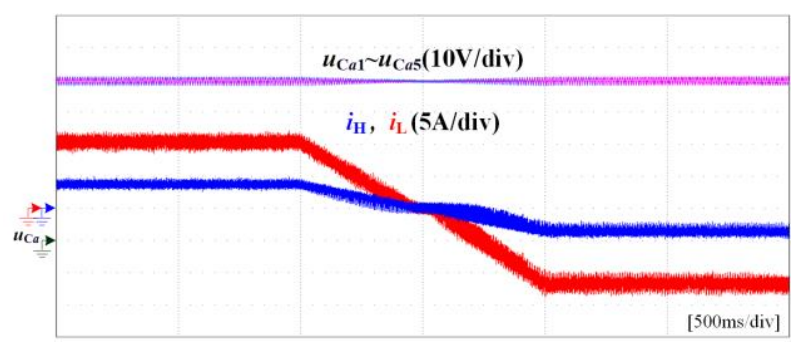

Fig. 13. Experimental results of the MS-HCDC under power reversal: currents of the two DC sides; capacitor voltages of the SMs $u_{\text {Ca1 }} \sim u_{\text {Ca5 }}$.

as shown in Fig. 7(b). These results verified the validity of the MS-HCDC and the control schemes.

Fig. 8 further shows the detailed waveforms of phase $a$ when the power flow is from the HV side to the LV side, which agree well with the theoretical waveforms in Fig. 3(c). $i_{P a}$ appears trapezoidal waveform with positive amplitude of $I_{\mathrm{H}}$ to charge the SMs in the string and with negative amplitude of $I_{\mathrm{L}}-I_{\mathrm{H}}$ to discharge them. The SM capacitors are designed according to (8), in which SM capacitor voltage ripple $\varepsilon$ is equal to $10 \%$. Besides, the SM capacitor voltages are well balanced, but it can be observed that in each cycle there are slight differences among them, this is due to the low switching frequency of each SM. Furthermore, the staircase-shaped waveform can be observed during the rising and falling transitions of $u_{P a}$, in which way the $\mathrm{d} v / \mathrm{d} t$ value is limited.

Fig. 9 displays the detailed waveforms of phase $a$ when the power flow is from the LV side to the HV side. The SM string is charged by the current $I_{\mathrm{L}}-I_{\mathrm{H}}$, and discharged by $I_{\mathrm{H}}$, thus $i_{P a}$ seems upside down compared with that in Fig. 8, and so do the currents of the IGBT branches.

Fig. 10 further shows the zoomed current, voltage, and gating signals of the IGBT branches. It can be observed that the gating signals are applied when the switch voltages and currents are both zero, which demonstrates the ZVZCS of $S_{a 1} \sim S_{a 4}$.

\section{EXPERIMENTAL VERIFICATION}

A downscaled prototype of the MS-HCDC rated at $2.4 \mathrm{~kW}$, $\pm 300 \mathrm{~V} / \pm 100 \mathrm{~V}$ has been built in the authors' laboratory, as shown in Fig. 11. Each of the four SM strings is composed of five half-bridge SMs. The test configuration is shown in Fig. 12, two regenerative DC power supplies with grounding resistors are connected with the MS-HCDC to emulate the monopolar 


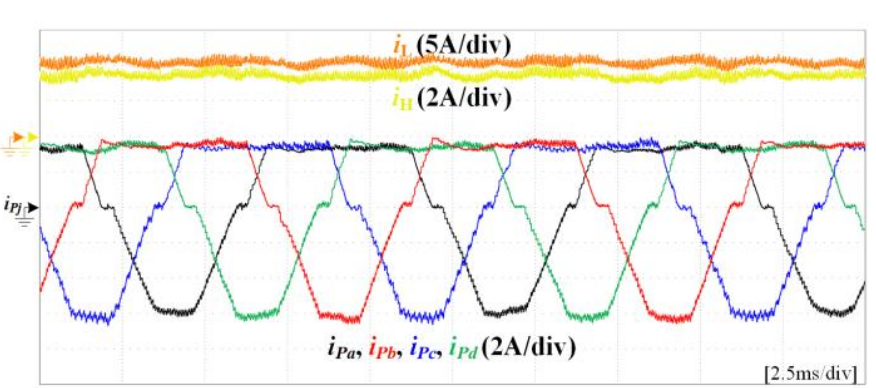

(a)

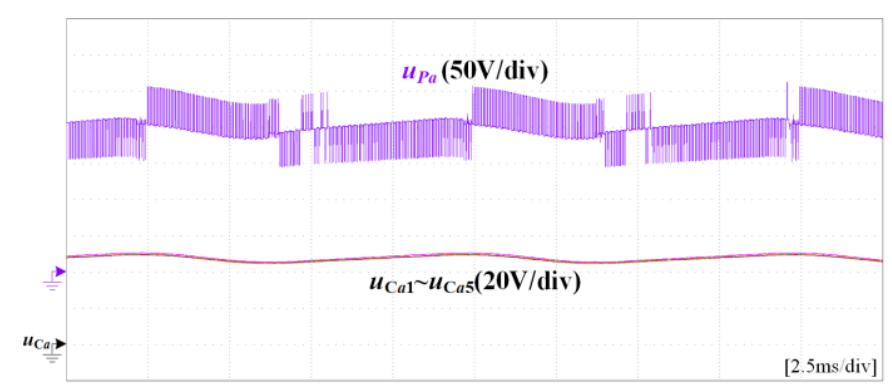

(b)

Fig. 14. Experimental results of the MS-HCDC when power is transmitted from the HV side to the LV side. (a) Currents of the two DC sides; currents of the SM strings; (b) String voltage $u_{P a}$; capacitor voltages of the SMs $u_{\mathrm{C} a 1} \sim u_{\mathrm{C} a 5}$.

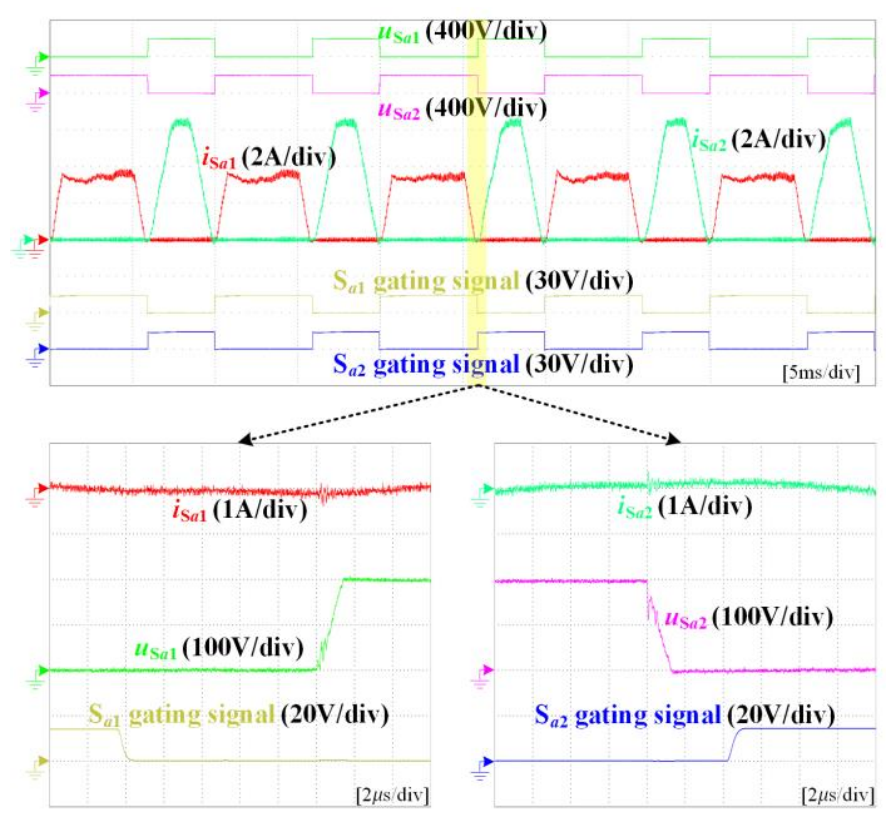

(a)

Fig. 16. Experimental results of the soft switching process of the IGBT branches. (a) $\mathrm{S}_{a 1}$ switching OFF and $\mathrm{S}_{a 2}$ switching ON; (b) $\mathrm{S}_{a 3}$ switching OFF and $\mathrm{S}_{a 4}$ switching ON.

symmetrical HVDC systems with different voltage ratings and a limiting resistor $\mathrm{R}_{\mathrm{s}}$ with bypass contactor $\mathrm{K}_{\mathrm{s}}$ is installed in series with the LV DC side of the proposed MS-HCDC, which is utilized to limit the inrush current into the capacitors during the start-up process of the MS-HCDC. The main circuit parameters are given in Table II. A digital signal processor TMS320F28377D DSP is employed to realize the control algorithms, and each SM is controlled by an independent EPM570T100 CPLD.

Fig. 13 presents the bidirectional power transfer performance

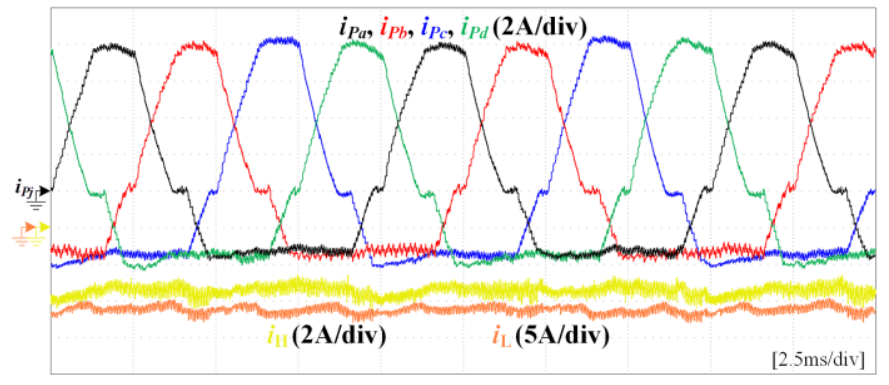

(a)

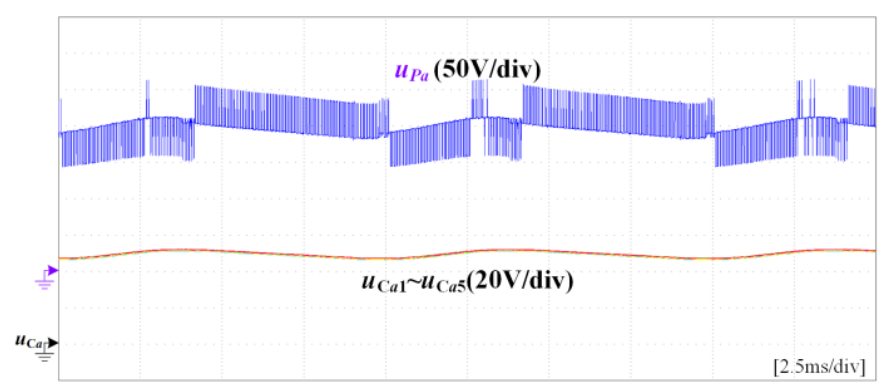

(b) the LV side to the HV side. (a) Currents of the two DC sides; currents of the SM strings; (b) String voltage $u_{P a}$; capacitor voltages of the SMs $u_{\mathrm{Ca} 1} \sim u_{\mathrm{Ca} a}$.

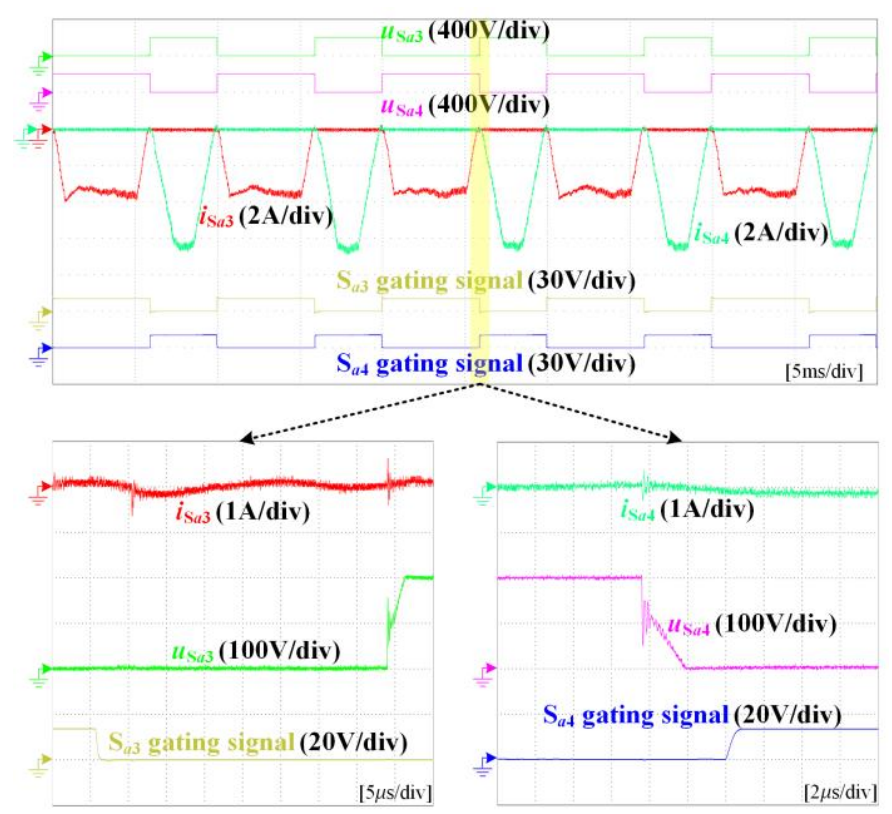

(b)

of the MS-HCDC. At the beginning, the MS-HCDC transmitted $2.4 \mathrm{~kW}$ power flow from the HV side to the LV side, and then the power flow was ramped down and kept reversed. In the whole process, the DC currents $i_{\mathrm{H}}$ and $i_{\mathrm{L}}$ followed the references and maintained stable. Nevertheless, some visible harmonics existed. This is due to the limited number (only five) of SMs in each string. For practical application with hundreds of SMs, the current harmonics would become negligible as a result of the sufficiently high number of levels in the string voltage. In addition, it can be observed the SM capacitor voltages were
Fig. 15. Experimental results of the MS-HCDC when power is transmitted from 


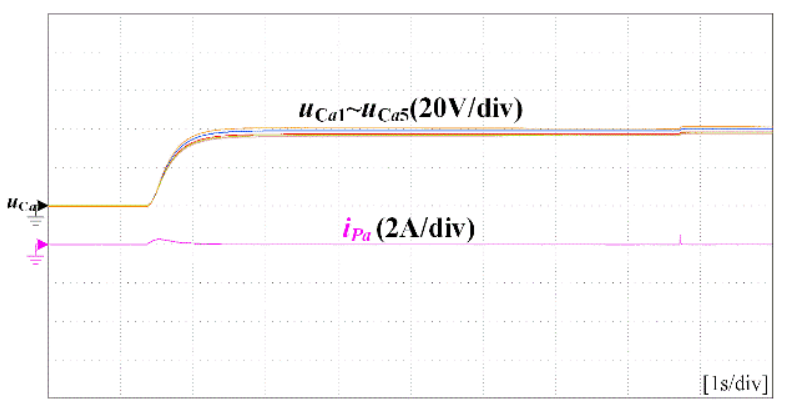

(a)

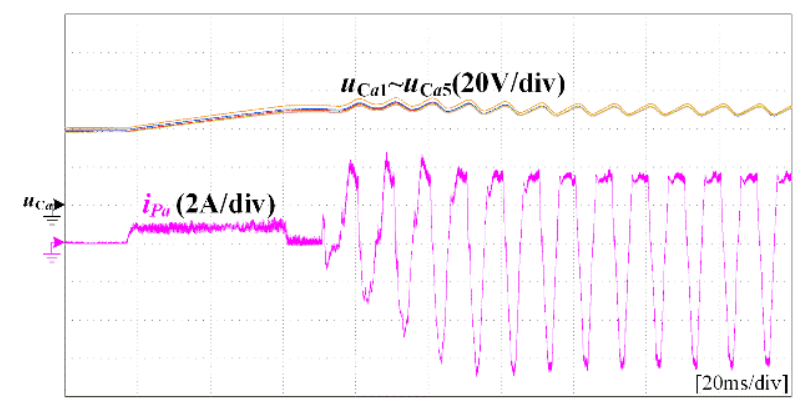

(b)

Fig. 17. Experimental results of the start-up process of the proposed MSHCDC. (a) Uncontrolled precharge stage; (b) Closed-loop precharge stage.

well balanced around $50 \mathrm{~V}$ during the entire power reversal process.

Fig. 14 presents the detailed steady-state waveforms of the MS-HCDC when power flow was transferred from the HV side to the LV side. The SM string current waveforms of the four phases were almost identical but interleaved with $90^{\circ}$ electrical angle, which generated continuous HV and LV DC currents $i_{\mathrm{H}}$ and $i_{\mathrm{L}}$. In addition, the peak-to-peak value of the SM capacitor voltages is about $5 \mathrm{~V}$, which agrees with the theoretical result in (8). On the other hand, Fig. 15 shows the detailed steady-state waveforms when power flow was transferred from the LV side to the HV side. The string current waveforms in Fig. 15(a) seem upside down compared with those in Fig. 14(a), meaning that the direction of the power flow was reversed. These results confirmed the effectiveness of the MS-HCDC topology and the proposed control schemes.

Fig. 16 displays the soft switching process of the IGBT branches. As shown in Fig. 16(a), $S_{a 1}$ was switched off before $u_{\mathrm{S} a 1}$ began to rise from zero, and $\mathrm{S}_{a 2}$ was switched on after $u_{\mathrm{S} a 2}$ fell to zero. As shown in Fig. 16(b), $\mathrm{S}_{a 3}$ was switched off before $u_{\mathrm{S} a 3}$ started to rise, and $\mathrm{S}_{a 4}$ was switched on after $u_{\mathrm{S} a 4}$ dropped to zero. Meanwhile, $i_{\mathrm{S} a 1} \sim i_{\mathrm{S} a 4}$ were basically zero during this process, thus $\mathrm{S}_{a 1} \sim \mathrm{S}_{a 4}$ can all be switched under ZVZCS condition. However, some resonant spikes are visible which are caused by the interaction between buffering inductance and parasitic capacitances, as well as the excitation of one voltage step of the $u_{\mathrm{Pa}}$ waveform (i.e., one SM voltage). As a result, this voltage spike cannot be higher than one SM voltage, hence it would not be a severe problem in the practical application with hundreds of SMs.

Fig. 17 shows the experimental results of the start-up precharge process of SM capacitors, in which phase $a$ is taken as an example. Fig. 17(a) shows the waveforms of the first uncontrolled precharge stage, during which the SM capacitors

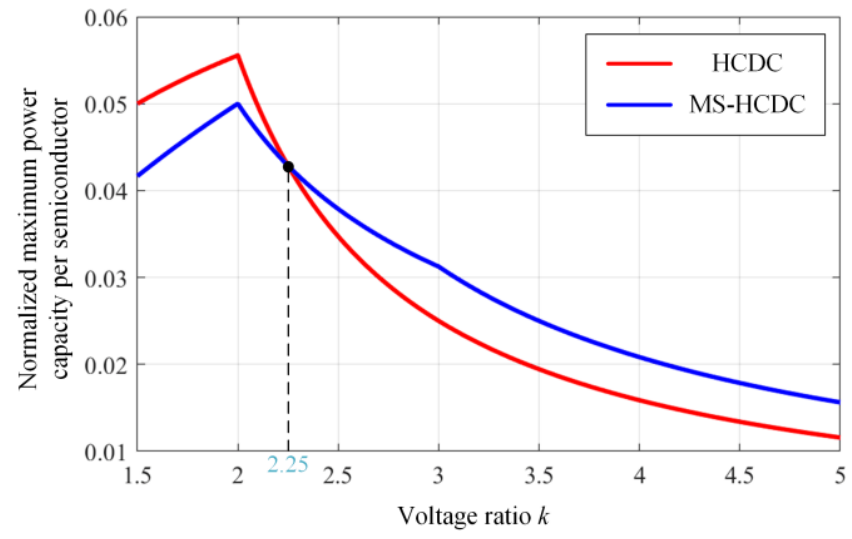

Fig. 18. The maximum power capacity per semiconductor of the traditional HCDC and the proposed MS-HCDC (normalized by $U_{\text {rated }} I_{\text {rated }}$ ).

TABLE III

COMPONENT COUNTS OF THE PROPOSED MS-HCDC AND THE HCDC

\begin{tabular}{l|c|c}
\hline \hline Quantity & $\begin{array}{c}\text { HCDC } \\
\text { topology [31] }\end{array}$ & $\begin{array}{c}\text { Proposed } \\
\text { MS-HCDC }\end{array}$ \\
\hline No. of SMs & $200 \times 6=\mathbf{1 2 0 0}$ & $200 \times 4=\mathbf{8 0 0}$ \\
No. of SM IGBTs & $1200 \times 2=\mathbf{2 4 0 0}$ & $800 \times 2=\mathbf{1 6 0 0}$ \\
No. of series-connected IGBTs & $318 \times 6=\mathbf{1 9 0 8}$ & $420 \times 4=\mathbf{1 6 8 0}$ \\
No. of buffering inductors & 6 & 4 \\
\hline \hline
\end{tabular}

can be precharged to about $40 \mathrm{~V}$ through the $40 \Omega$ limiting resistor. Fig. 17(b) shows the waveforms of the further controlled precharge stage. The charging current is closed-loop regulated as $1 \mathrm{~A}$ by adjusting the string voltage. Once the SM capacitors are fully charged to their rated capacitor voltage $50 \mathrm{~V}$, the proposed MS-HCDC turns into normal operation as the string current becomes trapezoid waveform.

\section{DISCUSSIONS}

\section{A. Comparison with the traditional HCDC}

In order to fairly compare the proposed MS-HCDC with the traditional HCDC, the maximum power capacity per semiconductor is used in this paper. It is assumed that the identical IGBTs are used and redundancy is not taken into consideration. According to (6), the maximum capacity of both the traditional HCDC and the proposed MS-HCDC can be expressed as

$$
P_{\max }=U_{\mathrm{H}} I_{\mathrm{H}}= \begin{cases}U_{\mathrm{H}} I_{\text {rated }} & \text { if } k \leq 2 \\ \frac{U_{\mathrm{H}} I_{\text {rated }}}{k-1} & \text { if } k>2\end{cases}
$$

where $I_{\text {rated }}$ is the rated current of the IGBTs and $k=U_{\mathrm{H}} / U_{\mathrm{L}}$ is the voltage ratio.

As for the traditional HCDC, the required number of SMs in each SM string is

$$
N_{\text {HCDC }}=\frac{\max \left[U_{\mathrm{H}}-U_{\mathrm{L}}, U_{\mathrm{L}}\right]}{U_{\text {rated }}} .
$$

where $U_{\text {rated }}$ is the rated voltage of the IGBTs and the extra current driving voltage $U_{1}$ and $U_{2}$ are ignored because they are relatively small compared to $U_{\mathrm{H}}$ and $U_{\mathrm{L}}$. 
And the number of series-connected IGBTs in each IGBT branch of the traditional HCDC can be calculated as

$$
\left\{\begin{array}{l}
N_{1,2_{-} \text {HCDC }}=\frac{U_{\mathrm{H}}-U_{\mathrm{L}}}{U_{\text {rated }}} \\
N_{3,4_{-} \text {HCDC }}=\frac{U_{\mathrm{L}}}{U_{\text {rated }}}
\end{array} .\right.
$$

Therefore, the maximum power capacity per semiconductor of the traditional HCDC can be derived as

$$
\begin{aligned}
M_{\mathrm{HCDC}} & =\frac{P_{\max }}{6 \times\left(2 N_{\mathrm{HCDC}}+2 N_{1,2 \_} \mathrm{HCDC}_{1,4}+2 N_{3 C D C}\right)} \\
& = \begin{cases}\frac{k}{12(k+1)} U_{\text {rated }} I_{\text {rated }} & \text { if } k \leq 2 . \\
\frac{k}{12(k-1)(2 k-1)} U_{\text {rated }} I_{\text {rated }} & \text { if } k>2\end{cases}
\end{aligned}
$$

Likewise, the maximum power capacity per semiconductor of the proposed MS-HCDC can be expressed as

$$
M_{\mathrm{MS}-\mathrm{HCDC}}=\left\{\begin{array}{ll}
\frac{k}{8(k+3)} U_{\text {rated }} I_{\text {rated }} & \text { if } k \leq 2 \\
\frac{k}{8(k+3)(k-1)} U_{\text {rated }} I_{\text {rated }} & \text { if } 2<k<3 \\
\frac{1}{16(k-1)} U_{\text {rated }} I_{\text {rated }} & \text { if } k \geq 3
\end{array} .\right.
$$

According to (15) and (16), Fig. 18 further shows the comparison results of maximum power capacity per semiconductor of the traditional HCDC and the proposed MSHCDC, which are normalized by $U_{\text {rated }} I_{\text {rated }}$. It is shown the maximum power capacity per semiconductor changes along with the voltage ratio $k$. The traditional HCDC has larger maximum power capacity per semiconductor if the voltage ratio is smaller than 2.25. On the contrary, the proposed MS-HCDC is better if the voltage ratio exceeds 2.25 . Larger maximum power capacity per semiconductor indicates higher utilization of semiconductors, so the proposed MS-HCDC is superior when the voltage ratio is larger than 2.25 .

\section{B. Specific case}

The simulated DC/DC conversion application in Section V ( $480 \mathrm{MW}, \pm 500 \mathrm{kV} / \pm 160 \mathrm{kV}$ ) is further studied to make a comparison between the proposed MS-HCDC and the traditional HCDC. The identical half-bridge SMs are chosen in the MS-HCDC and the traditional HCDC, whose nominal SM capacitor voltage is $U_{\mathrm{C}}=2 \mathrm{kV}$. For the MS-HCDC and the traditional HCDC, the numbers of half-bridge SMs in one phase are the same, which is 200 in this case study. However, the MSHCDC needs only four phases, while the traditional HCDC needs six phases in total (three phases for each pole). Thus, the number of SMs and SM IGBTs in the MS-HCDC can be reduced by $1 / 3$, as shown in Table III. However, it should be noted that the total energy stored in the SM capacitors in the proposed MS-HCDC is equal to that of the traditional HCDC, as then number of SMs is reduced, the SM capacitance of the proposed MS-HCDC should be 1.5 times that of the traditional
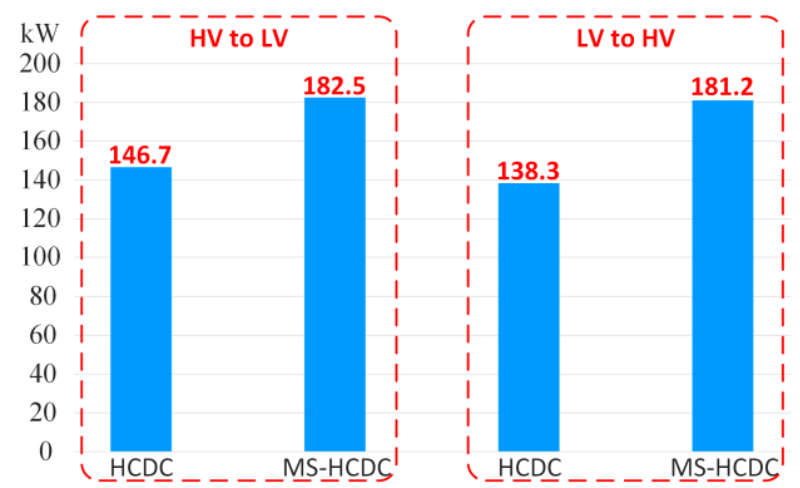

Fig. 19. Summation of the conduction losses of four IGBT branches in one phase in the traditional HCDC and the MS-HCDC.

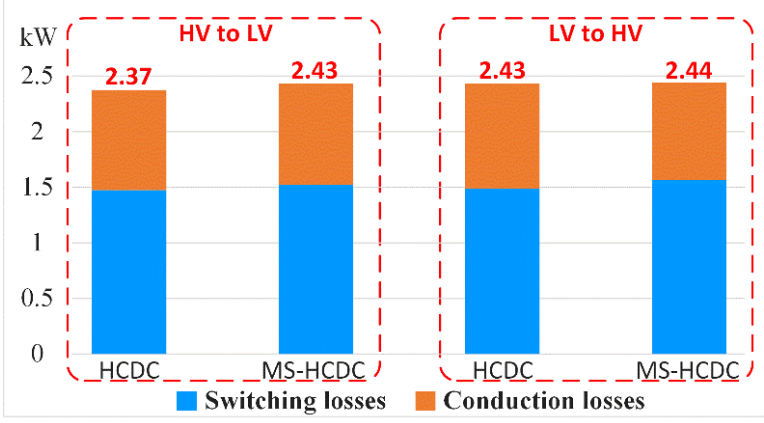

Fig. 20. Losses of each SM in the traditional HCDC and the MS-HCDC.

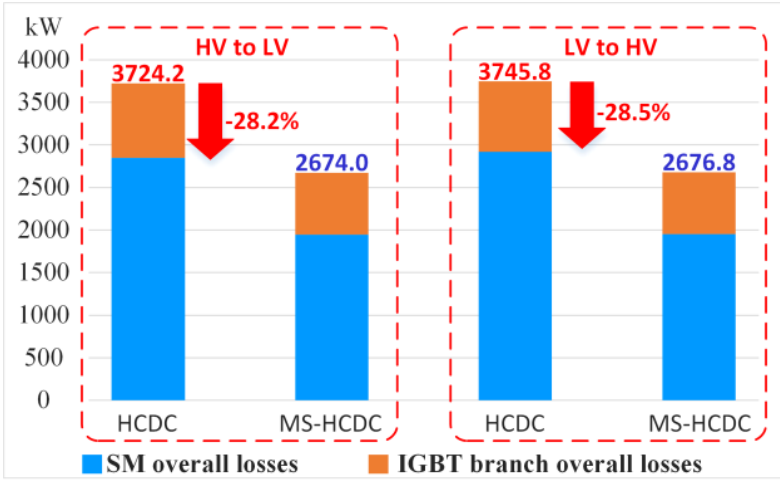

Fig. 21. Overall converter losses comparison.

HCDC. Consequently, compared to the traditional HCDC, the cost and volume corresponding to capacitors in the proposed MS-HCDC remain the same. However, since the number of SMs in the proposed MS-HCDC can be reduced significantly, the cost and volume corresponding to semiconductors and their auxiliary components (drivers, sensors, cooling devices, etc.) are saved. Therefore, the proposed MS-HCDC in general presents lower capital costs and smaller footprint.

The numbers of the series-connected IGBTs are also shown in Table III. The voltage rating of $S_{j 1}$ and $S_{j 2}$ in the MS-HCDC is the same with that in the $\mathrm{HCDC}$, while the voltage rating of $\mathrm{S}_{j 3}$ and $\mathrm{S}_{j 4}$ is twice that in the HCDC. Therefore, for a single phase, the MS-HCDC needs more series-connected IGBTs. However, since the number of phases is less, the MS-HCDC needs less series-connected IGBTs in total. It can be observed that the number of series-connected IGBTs in the MS-HCDC can be reduced by $12 \%$ compared with the traditional HCDC. 
In addition, the MS-HCDC requires only four buffering inductors, compared to the traditional HCDC which needs six.

Furthermore, the power losses of the proposed MS-HCDC and the traditional HCDC in the $480 \mathrm{MW}, \pm 500 \mathrm{kV} / \pm 160 \mathrm{kV}$ DC/DC conversion application are evaluated by co-simulation between MATLAB/SIMULINK and PLECS software. For the IGBT branch, ABB $4.5 \mathrm{kV} / 2 \mathrm{kA}$ press-pack IGBT module "5SNA2000K450300" is employed, and the ABB 3.3kV/1.5kA IGBT module "5SNA1500E330305" is used in the half-bridge SMs. For 5SNA 2000K450300 IGBT module, the junction-tocase and case-to-heatsink thermal resistances are $0.004 \mathrm{~K} / \mathrm{W}$ and $0.001 \mathrm{~K} / \mathrm{W}$, respectively, which are obtained from the datasheet [38]. For 5SNA 1500E330305 IGBT module, the IGBT junction-to-case and case-to-heatsink thermal resistances are $0.0085 \mathrm{~K} / \mathrm{W}$ and $0.009 \mathrm{~K} / \mathrm{W}$, respectively, and the diode junction-to-case and case-to-heatsink thermal resistances are $0.017 \mathrm{~K} / \mathrm{W}$ and $0.018 \mathrm{~K} / \mathrm{W}$, respectively, which are obtained from the datasheet [39]. The cooling water temperature of $40^{\circ} \mathrm{C}$ and heatsink-to-water thermal resistance of $5 \mathrm{~K} / \mathrm{kW}$ are assumed [40].

Fig. 19 demonstrates the summation of the power losses of four IGBT branches in one phase of the traditional HCDC and the MS-HCDC, respectively. Since the IGBTs operate under ZVZVS condition, only the conduction losses are taken into consideration. The conclusion can be drawn that the power losses of IGBT branches in a single phase of the MS-HCDC are higher than those of the HCDC. However, the MS-HCDC requires less phases, so the total losses of IGBT branches of the MS-HCDC are $82.94 \%$ of those of the HCDC when power is transmitted from the HV side to the LV side, and $87.35 \%$ in the reversed direction.

Fig. 20 presents the average losses of each SM in the traditional HCDC and the MS-HCDC, respectively. It is shown that for a single SM in the traditional HCDC and the proposed MS-HCDC, the power losses are similar. Whereas, the total power losses of SMs in the MS-HCDC are much lower because the number of SMs in the MS-HCDC is only $2 / 3$ of that of the traditional HCDC.

Adding the power losses of IGBT branches and all the SMs, the overall converter losses can be calculated, as shown in Fig. 21. As the power of the converter is $480 \mathrm{MW}$, the overall efficiency of the traditional HCDC is $99.22 \%$, while efficiency of the MS-HCDC is about $99.44 \%$. To summarize, compared with the traditional HCDC, the MS-HCDC can reduce the overall power losses by more than $28.2 \%$.

\section{CONCLUSION}

A monopolar symmetrical hybrid cascaded DC/DC converter (MS-HCDC) is proposed in this paper for interconnections of HVDC systems with different voltage ratings. The SM strings can be utilized by both of the positive and negative DC poles, thus only four phases are required compared to the traditional HCDC, which results in reduction of capital cost, power loss and footprint of the converter. Compared to the traditional HCDC, the proposed MS-HCDC has larger maximum power capacity per semiconductor when the voltage ratio is larger than 2.25 , which means the proposed MS-HCDC should be selected to obtain higher utilization of the semiconductors in this case. The operation principle and control strategies are discussed. Simulation and experimental results are performed which confirmed the validity and effectiveness of the MS-HCDC. The proposed MS-HCDC can be a promising "DC transformer" solution in the future monopolar symmetrical HVDC interconnections.

\section{REFERENCES}

[1] A. Lesnicar and R. Marquardt, "An innovative modular multilevel converter topology suitable for a wide power range," in Proc. IEEE Power Tech. Conf., Bologna, Italy, vol. 3, Jun. 23-26, 2003.

[2] J. Dorn, H. Gambach, J. Strauss, T. Westerweller, and J. Alligan, "Trans bay cable-A breakthrough of VSC multilevel converters in HVDC transmission," in Proc. CIGRE San Francisco Colloq., 2012.

[3] Z. Yao, Q. Zhang, P. Chen, Q. Zhao, "Research on fault diagnosis for MMC-HVDC systems," Protection and Control of Modern Power Systems, vol. 1, no. 1, pp. 71-77, Jun. 2016.

[4] G. Tang, Z. He, H. Pang, X. Huang and X.-P. Zhang, "Basic topology and key devices of the five-terminal dc grid," CSEE J. Power and Energy Sys., vol. 1, no. 1, pp. 22-35, Jun. 2015.

[5] M. H. Rahman, L. Xu, L. Yao, "Protection of large partitioned MTDC networks using DC-DC converters and circuit breakers," Protection and Control of Modern Power Systems, vol. 1, no. 1, pp. 170-178, Dec. 2016.

[6] D. Van Hertem and M. Ghandhari, "Multi-terminal VSC HVDC for the European supergrid: Obstacles," Renewable and Sustainable Energy Reviews, vol. 14, no. 9, pp. 3156-3163, 2010.

[7] T. M. Haileselassie and K. Uhlen, "Power system security in a meshed North Sea HVDC grid." Proc. IEEE, vol. 101, no. 4, pp. 978-990, Apr. 2013.

[8] H. Pang and X. Wei, "Research on key technology and equipment for Zhangbei 500kV DC grid," in 2018 International Power Electronics Conference (IPEC-Niigata 2018 -ECCE Asia), Niigata, 2018, pp. 23432351.

[9] N. Huang, Y. Wu, G. Lu, W. Wang and X. Cao, "Combined Probability Prediction of Wind Power Considering the Conflict of Evaluation Indicators," IEEE Access, vol. 7, pp. 174709-174724, Nov. 2019.

[10] C. D. Barker, C. D. Davidson, D. R. Trainer, and R. S. Whitehouse, "Requirements of DC-DC converters to facilitate large DC grids," in Proc. CIGRE Conf., 2012, pp. 1-10.

[11] J. D. Páez, D. Frey, J. Maneiro, S. Bacha and P. Dworakowski, "Overview of DC-DC converters dedicated to HVdc grids," IEEE Trans. Power Del., vol. 34, no. 1, pp. 119-128, Jun. 2019.

[12] G. P. Adam. I. A. Gowaid, S. J. Finney, D. Holliday, and B. W. Williams, "Review of dc-dc converters for multi-terminal HVDC transmission networks," IET Power Electron., vol. 9, no. 2, pp. 281-296, 2016.

[13] T. Luth, M.M.C. Merlin, T. C. Green, F. Hassan, and C. D. Barker, "Highfrequency operation of a DC/AC/DC system for HVDC applications," IEEE Trans. Power Electron., vol. 29, no. 8, pp. 4107-4115, Aug. 2014.

[14] S. Kenzelmann, A. Rufer, M. Vasiladiotis, D. Dujic, F. Canales, and Y. R. de Novaes, "Isolated DC/DC structure based on modular multilevel converter," IEEE Trans. Power Electron., vol. 30, no. 1, pp. 89-98, Jan. 2015.

[15] I. A. Gowaid, G. P. Adam, S. Ahmed, D. Holliday and B. W. Williams, "Analysis and design of a modular multilevel converter with trapezoidal modulation for medium and high voltage DC-DC transformers," IEEE Trans. Power Electron, vol. 30, no. 10, pp. 5439-5457, Oct. 2015.

[16] I. A. Gowaid, G. P. Adam, A. M. Massoud, S. Ahmed, D. Holliday, and B. W. Williams, "Quasi two-level operation of modular multilevel converter for use in a high-power dc transformer with dc fault isolation capability," IEEE Trans. Power Electron., vol. 30, no. 1, pp. 108-123, Jan. 2015.

[17] Z. Xing and X. Ruan, "Soft-switching operation of isolated modular DC/DC converters for application in HVDC grids," IEEE Trans. on Power Electron., vol. 31, no. 4, pp. 2753-2766, Apr. 2016.

[18] J. A. Ferreira, "The multilevel modular DC converter," IEEE Trans. on Power Electron., vol. 28, no. 10, pp. 4460-4465, Oct. 2013.

[19] G.J. Kish, M. Ranjram, and P.W. Lehn, "A modular multilevel DC/DC converter with fault blocking capability for HVDC interconnects," IEEE Trans. on Power Electron., vol. 30, no. 1, pp. 148-162, Jan. 2015.

[20] B. Li, S. Shi, Y. Zhang, R. Yang, G. Wang, and D. Xu, "Analysis of the operating principle and parameter design for the modular multilevel DC/DC converter," in Proc. ECCE Asia, 2015, pp. 2832-2837. 
[21] S. H. Kung and G. J. Kish, "A modular multilevel HVDC buck-boost converter derived from its switched-mode counterpart," IEEE Trans. on Power Del., vol. 33, no. 1, pp. 82-92, Feb. 2018.

[22] S. H. Kung and G. J. Kish, "Multiport modular multilevel converter for DC systems," IEEE Trans. Power Del., vol. 34, no. 1, pp. 73-83, Feb. 2019.

[23] S. Du and B. Wu, "A transformerless bipolar modular multilevel DC-DC converter with wide voltage ratios," IEEE Trans. Power Electron., vol. 32, no. 11, pp. 8312-8321, Nov. 2017.

[24] F. Zhang, W. Li and G. Joós, "A transformerless hybrid modular multilevel DC-DC converter with DC fault ride-through capability," IEEE Trans. Ind. Electron., vol. 66, no. 3, pp. 2217-2226, Mar. 2019.

[25] A. Schon and M.-M. Bakran, "A new HVDC-DC converter for the efficient connection of HVDC networks," in Proc. PCIM Europe Conf., Nurnberg, 2013, pp. 525-532.

[26] W. Lin, J. Wen, and S. Cheng, "Multiport dc-dc autotransformer for interconnecting multiple high-voltage dc systems at low cost," IEEE Trans. Power Electron., vol. 30, no. 12, pp. 6648-6660, Dec. 2015.

[27] G. J. Kish, "On the Emerging Class of Non-Isolated Modular Multilevel DC-DC Converters for DC and Hybrid AC-DC Systems," IEEE Trans. Smart Grid, vol. 10, no. 2, pp. 1762-1771, March. 2019.

[28] S. Du, B. Wu, K. Tian, D. Xu and N. R. Zargari, "A novel medium-voltage modular multilevel DC-DC converter," IEEE Trans. Ind. Electron., vol. 63, no. 12, pp. 7939-7949, Dec. 2016.

[29] S. Du, B. Wu, D. Xu and N. R. Zargari, "A transformerless bipolar multistring DC-DC converter based on series-connected modules," IEEE Trans. Power Electron., vol. 32, no. 2, pp. 1006-1017, Feb. 2017.

[30] S. Du, B. Wu, and N. Zargari, "A transformerless high-voltage DC-DC converter for DC grid interconnection," IEEE Trans. Power Del., vol. 33, no. 1, pp. 282-290, Feb. 2018.

[31] J. Yang, Z. He, H. Pang, and G. Tang, "The hybrid-cascaded DC-DC converters suitable for HVDC applications," IEEE Trans. on Power Electron., vol. 30, no. 10, pp. 5358-5363, Oct. 2015.

[32] K. Sharifabadi, L. Harnefors, H.-P. Nee, R. Teodorescu, and S. Norrga, Design, Control and Application of Modular Multilevel Converters for HVDC Transmission Systems. New York, USA: Wiley, 2016.

[33] J. Guo, J. Liang, X. Zhang, P. D. Judge, X. Wang and T. C. Green, "Reliability Analysis of MMCs Considering Submodule Designs with Individual or Series-Operated IGBTs," IEEE Trans. Power Del., vol. 32, no. 2, pp. 666-677, April 2017.

[34] B. Jacobson, P. Karlsson, G. Asplund, L. Harnefors, and T. Jonsson, "VSC-HVDC transmission with cascaded two-level converters," in CIGRE'Session, 2010, pp. B4-B110.

[35] J. Chivite-Zabalza, D. R. Trainer, J. C. Nicholls and C. C. Davidson, "Balancing Algorithm for a Self-Powered High-Voltage Switch Using Series-Connected IGBTs for HVDC Applications," IEEE Trans. Power Electron., vol. 34, no. 9, pp. 8481-8490, Sept. 2019.

[36] H. Yang and M. Saeedifard, "A capacitor voltage balancing strategy with minimized AC circulating current for the DC-DC modular multilevel converter," IEEE Trans. Ind. Electron., vol. 64, no. 2, pp. 956-965, Feb. 2017.

[37] M. Hagiwara and H. Akagi, "Control and Experiment of PulsewidthModulated Modular Multilevel Converters," IEEE Trans. Power Electron., vol. 24, no. 7, pp. 1737-1746, July 2009.

[38] "StakPak IGBT module 5SNA 2000K450300," ABB Switzerland, Ltd., Datasheet, Doc. No. 5SYA 1431-02 01-2018. [Online]. Available: www.abb.com.

[39] "HiPak IGBT module 5SNA 1500E330305," ABB Switzerland, Ltd., Datasheet, Doc. No. 5SYA 1407-07 02-2014. [Online]. Available: www.abb.com.

[40] S. Cui, N. Soltau, and R. W. D. Doncker, "A high step-up ratio softswitching dc-dc converter for interconnection of MVDC and HVDC grids," IEEE Trans. Power Electron., vol. 33, no. 4, pp. 2986-3001, Apr. 2018.

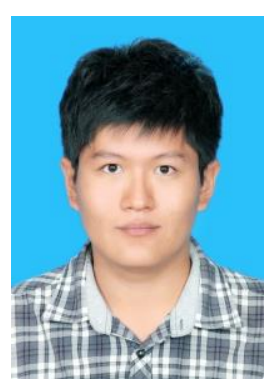

Shuxin Zhang received the B.S. and M.S. degrees in electrical engineering from Northeast Electric Power University, Jilin, China, in 2011 and 2016, respectively. He is currently pursuing the Ph.D. degree in electrical engineering at Harbin Institute of Technology. His research interests include modular multilevel converters, high voltage DC/DC converters and DC power flow controller.

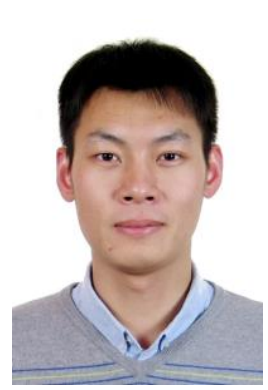

Binbin Li (S'15, M'17) received the B.S., M.S., and $\mathrm{Ph} . \mathrm{D}$. degrees in electrical engineering from the Harbin Institute of Technology, Harbin, China, in 2010, 2012, and 2017, respectively. From 2015 to 2016, he was a Visiting Researcher with the Department of Electronic and Electrical Engineering, University of Strathclyde, Glasgow, U.K. He is currently an Associate Professor with the Department of Electrical Engineering, Harbin Institute of Technology, and he has been selected in the Young Elite Scientists Sponsorship Program by China Association for Science and Technology. His research interests include modular power converters, HVDC grid, and MVDC collection/distribution system.

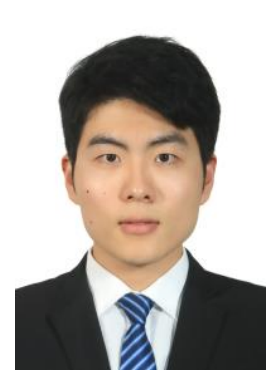

Da Cheng received the B.S. and M.S. degrees in electrical engineering from Harbin Institute of Technology, Harbin, China, in 2016 and 2019, respectively. $\mathrm{He}$ is an engineer at CRRC Qingdao SIFANG Rolling Stock Research Institute CO., LTD, Qingdao, China. His research interests include multilevel converters and DC/DC converters.



Xiaodong Zhao was born in 1996. He received the B.S. degree in electrical engineering from Harbin Engineering University, Harbin, China, in 2018. He is currently pursuing the Ph.D. degree in power electronics with the Harbin Institute of Technology, Harbin, China. His current research interests include solid-state transformers, high-power DC/DC Converter and modular multilevel converters.

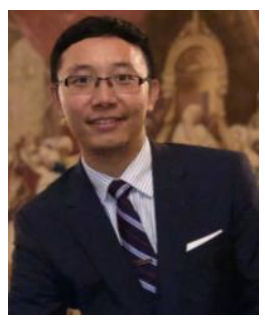

Gen Li (M'18) received the B.Eng. degree in Electrical Engineering and its Automation from Northeast Electric Power University, Jilin, China, in 2011, the M.Sc. degree in Power Engineering from Nanyang Technological University, Singapore, in 2013 and the Ph.D. degree in Electrical Engineering from Cardiff University, Cardiff, U.K., in 2018.

From 2013 to 2016, he was a Marie Curie Early Stage Research Fellow funded by the European Union's MEDOW project. He has been a Visiting Researcher at China Electric Power Research Institute and Global Energy Interconnection Research Institute, Beijing, China, at Elia, Brussels, Belgium and at Toshiba International (Europe), London, U.K. He has been a Research Associate at the School of Engineering, Cardiff University since 2017. His research interests include control and protection of HVDC and MVDC technologies, power electronics, reliability modelling and evaluation of power electronics systems.

Dr. Li is a Chartered Engineer in the U.K. He is an Associate Editor of the CSEE Journal of Power and Energy Systems. He is an Editorial board member of CIGRE ELECTRA. His Ph.D. thesis received the First CIGRE Thesis Award in 2018. 


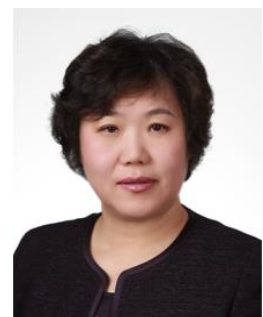

Wei Wang (M'13) received her B.S. degree in Automatic Test and Control from Harbin Institute of Technology, Harbin, China, in 1984, her M.S. degree in Electrical Engineering from Harbin Institute of Technology in 1990, and her Ph.D. degree in Mechanical Electronic Engineering from Harbin Institute of Technology in 2002. In 1984, she joined Harbin Institute of Technology, as an Assistant Professor in the Department of Electrical Engineering, where she was an Associate Professor from 1995 to 2003, and where she has been a Professor since 2003. Her current research interests include regenerative energy converter techniques, micro-grid, soft-switching converters, and lighting electronic technology.

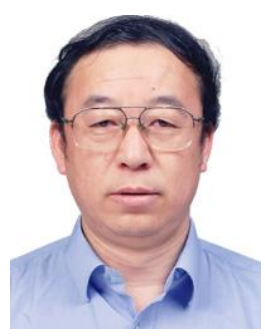

Dianguo Xu (M'97, SM'12, F'17) received the B.S. degree in Control Engineering from Harbin Engineering University, Harbin, China, in 1982, and the M.S. and Ph.D. degrees in Electrical Engineering from Harbin Institute of Technology (HIT), Harbin, China, in 1984 and 1989 respectively.

In 1984, he joined the Department of Electrical Engineering, HIT as an Assistant Professor. Since 1994, he has been a Professor in the Department of Electrical Engineering, HIT. He was the Dean of School of Electrical Engineering and Automation, HIT, from 2000 to 2010. He is currently the Vice President of HIT. His research interests include renewable energy generation technology, multi-terminal HVDC system based on VSC, power quality mitigation, speed sensorless vector controlled motor drives, high performance servo system. He has published over 600 technical papers.

Prof. $\mathrm{Xu}$ is an Associate Editor of the IEEE Transactions on Industrial Electronics, IEEE Transactions on Power Electronics, and the IEEE Journal of Emerging and Selected Topics in Power Electronics. He also serves as Chairman of IEEE Harbin Section. 